\title{
Genetic Determinants of Cortical Structure (Thickness, Surface Area and Volumes) among Disease Free Adults in the CHARGE Consortium
}

Edith Hofer*1,2, Gennady V. Roshchupkin*3,4,5, Hieab H. H. Adams*3,5, Maria J. Knol ${ }^{5}$, Honghuang Lin $^{6}$, Shuo Li ${ }^{7}$, Habil Zare ${ }^{8,9}$, Shahzad Ahmad ${ }^{5}$, Nicola J. Armstrong ${ }^{10}$, Claudia L. Satizabal ${ }^{30}$, Manon Bernard ${ }^{11}$, Joshua C. Bis ${ }^{12}$, Nathan A. Gillespie ${ }^{13,14}$, Michelle Luciano $^{15,16}$, Aniket Mishra ${ }^{17}$, Markus Scholz ${ }^{18,19}$, Alexander Teumer ${ }^{20}$, Rui Xia ${ }^{21}$, Xueqiu Jian $^{21}$, Thomas H. Mosley ${ }^{22}$, Yasaman Saba ${ }^{23}$, Lukas Pirpamer ${ }^{1}$, Stephan Seiler ${ }^{24,25}$, James T. Becker $^{26}$, Owen Carmichael ${ }^{27}$, Jerome I. Rotter ${ }^{28}$, Bruce M. Psaty ${ }^{29}$, Oscar L. Lopez ${ }^{26}$, Najaf Amin $^{5}$, Sven J. van der Lee ${ }^{5}$, Qiong Yang ${ }^{7}$, Jayandra J. Himali ${ }^{7}$, Pauline Maillard ${ }^{24,25}$, Alexa S. Beiser ${ }^{7,31}$, Charles DeCarli ${ }^{24,25}$, Sherif Karama ${ }^{32}$, Lindsay Lewis ${ }^{32}$,Mat Harris ${ }^{15,33,66,67}$, Mark E. Bastin ${ }^{15,33,66,67}$, Ian J. Deary ${ }^{15,16}$, A.Veronica Witte ${ }^{34,35}$, Frauke Beyer ${ }^{34,35}$, Markus Loeffler $^{18,19}$, Karen A. Mather ${ }^{36,37}$, Peter R. Schofield ${ }^{37,38}$, Anbupalam Thalamuthu ${ }^{36}$, John B. Kwok $^{39,38}$, Margaret J. Wright ${ }^{40,41}$, David Ames ${ }^{42,43}$, Julian Trollor ${ }^{36,44}$, Jiyang Jiang ${ }^{36}$, Henry Brodaty $^{45,36}$, Wei Wen ${ }^{36}$, Meike W Vernooij ${ }^{3,5}$, Albert Hofman ${ }^{46,5}$, André G. Uitterlinden ${ }^{5}$, Wiro J. Niessen ${ }^{47,3}$, Katharina Wittfeld ${ }^{48,49}$, Robin Bülow ${ }^{50}$, Uwe Völker ${ }^{51}$, Zdenka Pausova $^{11,52}$, G. Bruce Pike ${ }^{53}$, Sophie Maingault ${ }^{54}$, Fabrice Crivello ${ }^{54}$,Christophe Tzourio ${ }^{17,76}$, Philippe Amouye ${ }^{77,78,79}$, Bernard Mazoyer ${ }^{54}$, Michael C. Neale ${ }^{13}$, Carol E. Franz ${ }^{55}$, Michael J. Lyons ${ }^{56}$, Matthew S. Panizzon ${ }^{55}$, Ole A. Andreassen ${ }^{74}$, Anders M. Dale ${ }^{75}$, Mark Logue $^{57,58,7}$, Katrina L. Grasby ${ }^{59}$, Neda Jahanshad ${ }^{60}$, Jodie N. Painter ${ }^{59}$, Lucía ColodroConde $^{59}$, Janita Bralten ${ }^{61,62}$, Derrek P. Hibar ${ }^{60,63}$, Penelope A. Lind ${ }^{59}$, Fabrizio Pizzagalli ${ }^{60}$, Jason L. Stein ${ }^{64}$, Paul M. Thompson ${ }^{60}$, Sarah E. Medland ${ }^{59}$, ENIGMA consortium, Perminder S. Sachdev ${ }^{36,65}$, William S. Kremen ${ }^{55}$, Joanna M. Wardlaw ${ }^{15,33,66,67}$ Arno Villringer $^{34,68}$, Cornelia M. van Duijn ${ }^{5}$, Hans Jörgen Grabe ${ }^{49,48}$, William T. Longstreth Jr ${ }^{69}$, Myriam Fornage $^{21}$, Tomas Paus ${ }^{70,71}$, Stephanie Debette ${ }^{17,31,72}$, M. Arfan Ikram ${ }^{3,5,73}$, Helena Schmidt ${ }^{23}$, Reinhold Schmidt**1, Sudha Seshadri**30 
bioRxiv preprint first posted online Sep. 9, 2018; doi: http://dx.doi.org/10.1101/409649. The copyright holder for this preprint (which was not peer-reviewed) is the author/funder, who has granted bioRxiv a license to display the preprint in perpetuity.

It is made available under a CC-BY-NC-ND 4.0 International license.

${ }^{1}$ Clinical Division of Neurogeriatrics, Department of Neurology, Medical University of Graz, Graz, Austria

${ }^{2}$ Institute for Medical Informatics, Statistics and Documentation, Medical University of Graz, Graz, Austria

${ }^{3}$ Department of Radiology and Nuclear Medicine, Erasmus MC, Rotterdam, The Netherlands

${ }^{4}$ Department of Medical Informatics, Erasmus MC, Rotterdam, The Netherlands

${ }^{5}$ Department of Epidemiology, Erasmus MC, Rotterdam, The Netherlands

${ }^{6}$ Section of Computational Biomedicine, Department of Medicine, Boston University School of Medicine, Boston, MA, USA

${ }^{7}$ Department of Biostatistics, Boston University School of Public Health, Boston, MA, USA

${ }^{8}$ Glenn Biggs Institute for Alzheimer's and Neurodegenerative Diseases, UT Health San Antonio, San Antonio, USA

${ }^{9}$ Department of Cell Systems \& Anatomy, The University of Texas Health Science Center, San Antonio, Texas, USA

${ }^{10}$ Mathematics and Statistics, Murdoch University, Perth, Australia

${ }^{11}$ Hospital for Sick Children, Toronto, Canada

${ }^{12}$ Cardiovascular Health Research Unit, Department of Medicine, University of Washington, Seattle, WA, USA

${ }^{13}$ Virginia Institute for Psychiatric and Behavior Genetics, Virginia Commonwealth University, VA, USA

${ }^{14}$ QIMR Berghofer Medical Research Institute, QLD, Australia

${ }^{15}$ Centre for Cognitive Epidemiology and Cognitive Ageing, University of Edinburgh, Edinburgh, UK

${ }^{16}$ Department of Psychology, University of Edinburgh, Edinburgh, UK

${ }^{17}$ University of Bordeaux, Bordeaux Population Health Research Center, INSERM UMR

1219, Bordeaux, France

${ }^{18}$ Institute for Medical Informatics, Statistics and Epidemiology, University of Leipzig, Leipzig, Germany

${ }^{19}$ LIFE Research Center for Civilization Diseases, University of Leipzig, Leipzig, Germany

${ }^{20}$ Institute for Community Medicine, University Medicine Greifswald, Greifswald, Germany

${ }^{21}$ Institute of Molecular Medicine and Human Genetics Center, University of Texas Health Science Center at Houston, Houston, TX, USA

${ }^{22}$ Department of Medicine, University of Mississippi Medical Center, Jackson, MS, USA 
bioRxiv preprint first posted online Sep. 9, 2018; doi: http://dx.doi.org/10.1101/409649. The copyright holder for this preprint (which was not peer-reviewed) is the author/funder, who has granted bioRxiv a license to display the preprint in perpetuity.

It is made available under a CC-BY-NC-ND 4.0 International license.

${ }^{23}$ Gottfried Schatz Research Center for Cell Signaling, Metabolism and Aging, Medical University of Graz, Graz, Austria

${ }^{24}$ Imaging of Dementia and Aging (IDeA) Laboratory, Department of Neurology, University of California-Davis, Davis, CA, USA

${ }^{25}$ Department of Neurology and Center for Neuroscience, University of California at Davis, Sacramento, CA, USA

${ }^{26}$ Departments of Psychiatry, Neurology, and Psychology, University of Pittsburgh, Pittsburgh, PA, USA

${ }^{27}$ Pennington Biomedical Research Center, Baton Rouge, LA, USA

${ }^{28}$ Institute for Translational Genomics and Population Sciences, Los Angeles Biomedical Research Institute and Pediatrics at Harbor-UCLA Medical Center, Torrance, CA, USA

${ }^{29}$ Cardiovascular Health Research Unit, Departments of Medicine, Epidemiology and Health Services, University of Washington, Seattle, WA, USA

${ }^{30}$ Department of Epidemiology and Biostatistics, Glenn Biggs Institute for Alzheimer's and Neurodegenerative Diseases, UT Health San Antonio, San Antonio, USA

${ }^{31}$ Department of Neurology, Boston University School of Medicine, Boston, MA, USA

${ }^{32}$ McGill University, Montreal Neurological Institute, Montreal, Canada

${ }^{33}$ Centre for Clinical Brain Sciences, University of Edinburgh, Edinburgh, UK

${ }^{34}$ Department of Neurology, Max Planck Institute for Human Cognitive and Brain Sciences, Leipzig, Germany

${ }^{35}$ Faculty of Medicine, CRC 1052 Obesity Mechanisms, University of Leipzig, Leipzig, Germany

${ }^{36}$ Centre for Healthy Brain Ageing,School of Psychiatry, University of New South Wales, Sydney, Australia

${ }^{37}$ Neuroscience Research Australia, Sydney, Australia

${ }^{38}$ School of Medical Sciences, University of New South Wales, Sydney, Australia

${ }^{39}$ Brain and Mind Centre - The University of Sydney, Camperdown, NSW, Australia

${ }^{40}$ Queensland Brain Institute, The University of Queensland, St Lucia, QLD, Australia

${ }^{41}$ Centre for Advanced Imaging, The University of Queensland, St Lucia, QLD, Australia

${ }^{42}$ National Ageing Research Institute, Royal Melbourne Hospital, Victoria, Australia

${ }^{43}$ Academic Unit for Psychiatry of Old Age, University of Melbourne, St George's Hospital, Kew, Australia 
${ }^{44}$ Department of Developmental Disability Neuropsychiatry, School of Psychiatry,

University of New South Wales, Sydney, Australia

${ }^{45}$ Dementia Centre for Research Collaboration, University of New South Wales, Sydney, NSW, Australia

${ }^{46}$ Department of Epidemiology, Harvard T.H. Chan School of Public Health, Boston, MA, USA

${ }^{47}$ Imaging Physics, Faculty of Applied Sciences, Delft University of Technology, The Netherlands

${ }^{48}$ German Center for Neurodegenerative Diseases (DZNE), Site Rostock/ Greifswald, Germany

${ }^{49}$ Department of Psychiatry and Psychotherapy, University Medicine Greifswald, Germany

${ }^{50}$ Institute for Diagnostic Radiology and Neuroradiology, University Medicine Greifswald, Greifswald, Germany

${ }^{51}$ Interfaculty Institute for Genetics and Functional Genomics, University Medicine

Greifswald, Greifswald, Germany

52 Departments of Physiology and Nutritional Sciences, University of Toronto, Toronto,

Canada

${ }^{53}$ Departments of Radiology and Clinial Neurosciences, University of Calgary, Calgary,

Canada

${ }^{54}$ Institut des Maladies Neurodégénratives UMR5293, CEA, CNRS, University of Bordeaux, Bordeaux, France

${ }^{55}$ Department of Psychiatry, University of California San Diego, CA, USA

${ }^{56}$ Department of Psychological and Brain Sciences, Boston University, Boston, MA, USA

${ }^{57}$ National Center for PTSD at Boston VA Healthcare System, Boston, MA, USA

${ }^{58}$ Department of Psychiatry and Department of Medicine-Biomedical Genetics Section,

Boston University School of Medicine, Boston MA, USA

${ }^{59}$ Psychiatric Genetics, QIMR Berghofer Medical Research Institute, Brisbane, Australia

${ }^{60}$ Imaging Genetics Center, Mark and Mary Stevens Neuroimaging and Informatics Institute, Keck School of Medicine of USC, University of Southern California, Los Angeles, CA, USA

${ }^{61}$ Department of Human Genetics, Radboud university medical center, Nijmegen, The

Netherlands

${ }^{62}$ Donders Institute for Brain, Cognition and Behaviour, Radboud University, Nijmegen, The Netherlands 
${ }^{63}$ Neuroscience Biomarkers, Janssen Research and Development, LLC, San Diego, USA

${ }^{64}$ Department of Genetics \& UNC Neuroscience Center, University of North Carolina at Chapel Hill, Chapel Hill, USA

${ }^{65}$ Neuropsychiatric Institute, Prince of Wales Hospital, Sydney, Australia

${ }^{66}$ Brain Research Imaging Centre, University of Edinburgh, Edinburgh, UK

${ }^{67}$ Scottish Imaging Network, A Platform for Scientific Excellence (SINAPSE) Collaboration, Department of Neuroimaging Sciences, The University of Edinburgh, Edinburgh, UK

${ }^{68}$ Day Clinic for Cognitive Neurology, University Hospital Leipzig, Leipzig, Germany

${ }^{69}$ Departments of Neurology and Epidemiology, University of Washington, Seattle, WA, USA

${ }^{70}$ Bloorview Research Institute, Holland Bloorview Kids Rehabilitation Hospital, Toronto, Ontario, Canada

${ }^{71}$ Departments of Psychology and Psychiatry, University of Toronto, Toronto, Canada

${ }^{72}$ CHU de Bordeaux, Department of Neurology, F-33000 Bordeaux, France

${ }^{73}$ Department of Neurology, Erasmus MC, Rotterdam, the Netherlands

${ }^{74}$ NORMENT, KG Jebsen Centre for Psychosis Research, Institute of Clinical Medicine, University of Oslo and Division of Mental Health and Addiction, Oslo University Hospital, Oslo, Norway

${ }^{75}$ Departments of Radiology and Neurosciences, University of California, San Diego, La Jolla, CA, USA

${ }^{76}$ Pole de santé publique, Centre Hospitalier Universitaire de Bordeaux, Bordeaux, France

${ }^{77}$ Centre Hospitalier Universitaire de Bordeaux, France; Inserm U1167, Lille, France

${ }^{78}$ Department of Epidemiology and Public Health, Pasteur Institute of Lille, Lille, France

${ }^{79}$ Department of Public Health, Lille University Hospital, Lille, France

*these authors contributed equally to this work

**these authors jointly supervised the work 


\section{Abstract}

Cortical thickness, surface area and volumes (MRI cortical measures) vary with age and cognitive function, and in neurological and psychiatric diseases. We examined heritability, genetic correlations and genome-wide associations of cortical measures across the whole cortex, and in 34 anatomically predefined regions. Our discovery sample comprised 22,824 individuals from 20 cohorts within the Cohorts for Heart and Aging Research in Genomic Epidemiology (CHARGE) consortium and the United Kingdom Biobank. Significant associations were replicated in the Enhancing Neuroimaging Genetics through Meta-analysis (ENIGMA) consortium, and their biological implications explored using bioinformatic annotation and pathway analyses. We identified genetic heterogeneity between cortical measures and brain regions, and 160 genome-wide significant associations pointing to wnt/ $\beta$ catenin, TGF- $\beta$ and sonic hedgehog pathways. There was enrichment for genes involved in anthropometric traits, hindbrain development, vascular and neurodegenerative disease and psychiatric conditions. These data are a rich resource for studies of the biological mechanisms behind cortical development and aging. 


\section{Introduction}

The cortex is the largest part of the human brain, associated with higher brain functions such as perception, thought and action. Brain cortical thickness (CTh), cortical surface area (CSA) and cortical volume $(\mathrm{CV})$ are morphological markers of cortical structure obtained from magnetic resonance imaging (MRI). These measures change with age $\mathrm{e}^{1-3}$ and are linked to cognitive functioning ${ }^{4,5}$. The human cortex is also vulnerable to a wide range of disease or pathologies, ranging from developmental disorders and early onset psychiatric and neurological diseases to neurodegenerative conditions manifesting late in life. Abnormalities in global or regional CTh, CSA and CV have been observed in neurological and psychiatric disorders such as Alzheimer's disease ${ }^{6,7}$, Parkinson's disease ${ }^{8,9}$, multiple sclerosis $^{10,11}$, schizophrenia $^{12,13}$, bipolar disorder ${ }^{12,14,15}$, depression ${ }^{15,16}$ and autism ${ }^{17,18}$. The best method to study human cortical structure during life is using brain MRI. Hence, understanding the genetic determinants of the most robust MRI cortical markers in apparently normal adults could identify biological pathways relevant to brain development, aging and various diseases. Neurons in the neocortex are organized in columns which run perpendicular to the surface of the cerebral cortex ${ }^{19}$; and, according to the radial unit hypothesis, CTh is determined by the number of cells within the columns and CSA is determined by the number of columns ${ }^{20}$. Thus, CTh and CSA reflect different mechanisms in cortical development ${ }^{20-24}$ and are likely influenced by different genetic factors ${ }^{25,26}$. CV, which is the product of CTh and CSA, is determined by a combination of these two measures, but the relative contribution of CTh and CSA to CV may vary across brain regions. $\mathrm{CTh}, \mathrm{CSA}$ and $\mathrm{CV}$ are all strongly heritable traits $^{22,24-30}$ with estimated heritability of 0.69 to 0.81 for global CTh, and from 0.42 to 0.90 for global CSA ${ }^{24-26}$. Across different cortical regions however, there is substantial regional variation in heritability of CTh, CSA and $\mathrm{CV}^{22,24-30}$. Since CTh, CSA and CV are differentially heritable and genetically heterogeneous, we explored the genetics of each of 
bioRxiv preprint first posted online Sep. 9, 2018; doi: http://dx.doi.org/10.1101/409649. The copyright holder for this preprint (which was not peer-reviewed) is the author/funder, who has granted bioRxiv a license to display the preprint in perpetuity. It is made available under a CC-BY-NC-ND 4.0 International license.

these imaging markers using genome-wide association analyses in large population-based samples (GWAS). We studied CTh, CSA and CV in the whole cortex and in 34 cortical regions in 22,824 individuals from 21 discovery cohorts and replicated the strongest associations in 22,363 persons from the ENIGMA consortium. 


\section{Results}

\section{Genome-wide association analysis}

Global Cortical Measures: The analyses of global CTh, CSA and CV included 22,163, 18,617 and 22,824 individuals respectively. After a conservative correction for multiple testing $\left(\mathrm{p}_{\text {discovery }}<1.09 \times 10^{-9}\right)$, we identified no significant associations with global CTh. However, we identified 12 independent loci associated with global CSA $(n=6)$ and CV $(n=6)$. These are displayed in Table S8 and Supplementary Figures 1 and 2. Five of the 6 CSA loci were replicated in an external (ENIGMA consortium) sample ${ }^{31}$. The ENIGMA consortium only analyzed CSA and CTh.

Regional Cortical Measures: GWAS of CTh, CSA and CV in 34 cortical regions of interest (ROIs) identified 148 significant associations. There were 16 independent loci across 8 chromosomes determining CTh of 9 regions (Table S9), 54 loci across 16 chromosomes associated with CSA of 21 regions (Table S10), and 78 loci across 17 chromosomes determining CV of 23 cortical regions (Table S11). We replicated 57 out of 70 regional CTh and CSA loci in the ENIGMA consortium sample ${ }^{31}$ using a conservative replication threshold of $p_{\text {Replication }}=3.1 \times 10^{-4}, 0.05 / 160$. Region-specific variants with the strongest association at each genomic locus are shown in Tables 1-3. Chromosomal ideograms showing genomewide significant associations with global and regional cortical measures in the discovery stage are presented in Figure 1.

The strongest associations with CTh and CV were observed for rs2033939 at 15q14 (piscovery, $\mathrm{CTh}=1.17 \times 10^{-73}$ and pDiscovery, $\mathrm{CV}=4.34 \times 10^{-133}$ ) in the postcentral (primary somatosensory) cortex, and for CSA with rs1080066 at $15 \mathrm{q} 14$ ( piscovery, $\left.\mathrm{CSA}=8.45 \times 10^{-109}\right)$ in the precentral (primary motor) cortex. Figure 2 shows the lowest p-value of each cortical region. The postcentral cortex was also the region with the largest number of independent associations, mainly at a locus on $15 \mathrm{q} 14$. The corresponding regional association plots are presented in 
Supplementary Figure 3.

QQ plots of all meta-analyses are presented in Supplementary Figures 4-7.

Associations across Cortical Measures and with Other Traits: Table S12 presents variants which are associated with the CSA or the CV across multiple regions. We observed 25 SNPs that determined both the CSA and CV of a given region, 4 SNPs that determined CTh and CV of the same region, but no SNPs that determined both the CTh and CSA of any given region (Table S13). In the UK Biobank ${ }^{32}, 3$ SNPs were associated with the same cortical measure at a given cortical region as in our study. These included associations between rs2033939 at 15q14 and postcentral CTh, rs2279829 at 3q24 and CSA of the pars triangularis and postcentral gyrus and rs76341705 at 14q23.1 and CSA of lingual gyrus, respectively (Table S14). When assessing genetic overlap with other traits, we observed that SNPs determining these cortical measures have been previously associated with anthropometric (height), neurologic (Parkinson's disease, corticobasal degeneration, Alzheimer's disease), psychiatric (neuroticism, schizophrenia) and cognitive performance traits as well as with total intracranial volume (TIV) on brain MRI (Tables S15-S17).

\section{Gene Identification}

Positional mapping based on ANNOVAR showed that most of the lead SNPs were intergenic and intronic (Figure 3). One variant, rs2279829, which was associated with both CSA and $\mathrm{CV}$ of the pars triangularis, postcentral and supramarginal cortices, is located in the 3 'prime UTR of ZIC4 at 3q24. We also found an exonic variant, rs10283100, in gene ENPP2 at 8q24.12 associated with CV of the insula.

We used multiple strategies beyond positional annotation to identify specific genes implicated by the various GWAS associated SNPs. FUMA identified 232 genes whose 
bioRxiv preprint first posted online Sep. 9, 2018; doi: http://dx.doi.org/10.1101/409649. The copyright holder for this preprint (which was not peer-reviewed) is the author/funder, who has granted bioRxiv a license to display the preprint in perpetuity.

It is made available under a CC-BY-NC-ND 4.0 International license.

expression was determined by these variants (eQTL) and these and other genes implicated by chromatin interaction mapping are shown in Tables S18-S20. MAGMA gene-based association analyses revealed 70 significantly associated $\left(\mathrm{p}<5.87^{*} 10^{-8}\right)$ genes (Tables S21S23). For global CSA and CV, 7 of 9 genes associated with each measure overlapped, but there was no overlap with global CTh. For regional CSA and CV we found 28 genes across 13 cortical regions that determined both measures in the same region. Figure 4 summarizes the results of GTEx eQTL, chromatin interaction, positional annotation and gene-based mapping strategies for all regions. While there are overlapping genes identified using different approaches, only DAAM1 gene (Chr14q23.1) is identified by all types of gene mapping for CV of insula. eQTL associations of our independent lead SNPs in the Religious Orders Study- Memory and Aging Project dorsolateral frontal cortex gene expression dataset are presented in Table S24.

\section{Pathway analysis}

MAGMA gene set analyses identified 7 pathways for CTh, 3 pathways for CSA and 9 pathways for CV (Table S25). Among them are the Gene Ontology (GO) gene sets 'hindbrain morphogenesis' (strongest association with thickness of middle temporal cortex), 'forebrain generation of neurons' (with surface area of precentral cortex), and 'central nervous system neuron development' (with volume of transverse temporal cortex). However, after Bonferroni correction only one significant pathway $\left(\mathrm{p}<1.02 \times 10^{-7}\right)$ remained: 'regulation of catabolic process' for CTh of inferior temporal cortex. InnateDB pathway analyses of genes mapped to independent lead SNPs by FUMA showed a significant overlap between CTh and CSA genes and the Wnt signaling pathway (Supplementary Figures 8 and 9) as well as a significant overlap between CV genes and the basal cell carcinoma pathway (Supplementary Figure 10). 


\section{Heritability}

Heritability estimates $\left(\mathrm{h}^{2}\right)$ of global CTh were $0.64\left(\mathrm{se}=0.12 ; \mathrm{p}=3 \times 10^{-7}\right)$ in ASPS-Fam and $0.45\left(\mathrm{se}=0.08 ; \mathrm{p}=2.5 \times 10^{-7}\right)$ in RS. For CSA, $\mathrm{h}^{2}$ was $0.84\left(\mathrm{se}=0.12 ; \mathrm{p}=2.63 \times 10^{-11}\right)$ in ASPSFam and $0.33\left(\mathrm{se}=0.08, \mathrm{p}=1 \times 10^{-4}\right)$ in $\mathrm{RS}$, and for $\mathrm{CV}, \mathrm{h}^{2}$ was $0.80\left(\mathrm{se}=0.11 ; \mathrm{p}=1.10 \times 10^{-9}\right)$ in ASPS-Fam and $0.32\left(\mathrm{se}=0.08 ; \mathrm{p}=1 \times 10^{-4}\right)$ in $\mathrm{RS}$. There was a large range in heritability estimates of regional CTh, CSA and CV (Table S26).

Heritability based on common SNPs as estimated with LDSR was $0.25(\mathrm{se}=0.03)$ for global CTh, $0.29(\mathrm{se}=0.04)$ for global CSA and $0.30(\mathrm{se}=0.03)$ for global CV. LDSR heritability estimates of regional CTh, CSA and CV are presented in Table S26 and Supplementary Figure 11. For the regional analyses, the estimated heritability ranged from 0.05 to 0.18 for CTh, from 0.07 to 0.36 for CSA and from 0.06 to 0.32 for CV. Superior temporal cortex $\left(\mathrm{h}^{2}{ }_{\mathrm{CTh}}=0.18, \mathrm{~h}^{2}{ }_{\mathrm{CSA}}=0.30, \mathrm{~h}_{\mathrm{CV}}^{2}=0.26\right)$, precuneus $\left(\mathrm{h}^{2}{ }_{\mathrm{CTh}}=0.16, \mathrm{~h}^{2}{ }_{\mathrm{CSA}}=0.29, \mathrm{~h}^{2}{ }_{\mathrm{CV}}=0.28\right)$ and pericalcarine $\left(\mathrm{h}^{2} \mathrm{CTh}=0.15, \mathrm{~h}^{2}{ }_{\mathrm{CSA}}=0.36, \mathrm{~h}_{\mathrm{CV}}^{2}=0.32\right)$ are among the most genetically determined regions.

The results of partitioned heritability analyses for global and regional CTh, CSA and CV with functional annotation and additionally with cell-type specific annotation are presented in Tables S27 and S28. For global CTh we found enrichment for super-enhancers, introns and histone marks. Repressors and histone marks were enriched for global CSA, and introns, super-enhancers and repressors for global CV. For regional CSA and CV the highest enrichment scores $(>18)$ were observed for conserved regions.

\section{Genetic correlation}

We found high genetic correlation $\left(\mathrm{r}_{\mathrm{g}}\right)$ between global CSA and global CV $\left(\mathrm{r}_{\mathrm{g}}=0.81\right.$, $\left.\mathrm{p}=1.2 \times 10^{-186}\right)$ and between global CTh and global $\mathrm{CV}\left(\mathrm{r}_{\mathrm{g}}=0.46, \mathrm{p}=1.4 \times 10^{-14}\right)$, but not between global CTh and global CSA $\left(\mathrm{r}_{\mathrm{g}}=-0.02, \mathrm{p}=0.82\right)$. Whereas genetic correlation 
between CSA and CV was strong $\left(r_{g}>0.7\right)$ in most of the regions (Table S29 and Supplementary Figure 12), it was generally weak between CSA and CTh with $\mathrm{r}_{\mathrm{g}}<0.3$, and ranged from 0.09 to 0.69 between $\mathrm{CTh}$ and $\mathrm{CV}$. The postcentral and lingual cortices were the two regions with the highest genetic correlations between both $\mathrm{CTh}$ and $\mathrm{CV}$, as well as $\mathrm{CTh}$ and CSA.

Genetic correlation across the various brain regions for CTh (Supplementary Figure 13, Table S30), CSA (Supplementary Figure 14, Table S30), and CV (Supplementary Figure 15, Table S32) showed a greater number of correlated regions for CTh and greater inter-regional variation for CSA and CV. Tables S33 - S35 and Supplementary Figures 16-18 show genome-wide genetic correlations between the cortical measures and anthropometric, neurological and psychiatric, and cerebral structural traits. 


\section{Discussion}

In our genome-wide association study of up to 22,824 individuals for MRI determined cortical measures of global and regional thickness, surface area and volume, we identified 160 genome-wide significant associations across 19 chromosomes. Heritability was generally higher for cortical surface area and volume than for thickness, suggesting a greater susceptibility of cortical thickness to environmental influences. We observed strong genetic correlations between surface area and volume, but weak genetic correlation between surface area and thickness. We identified the largest number of novel genetic associations with cortical volumes, perhaps due to our larger sample size for this phenotype which was assessed in all 21 discovery samples.

It is beyond the scope of our study to discuss each of the 160 associations identified. However, broad patterns emerged showing that genes determining cortical structure are also often implicated in development of the cerebellum and brainstem (KIAA0586, ZIC4, ENPP2) as well as the neural tube (one carbon metabolism genes DHFR and MSRBB3, the latter also associated with hippocampal volumes ${ }^{33}$ ). These genes determine development of not only neurons but also astroglia (THBS1) and microglia (SALL1). They determine susceptibility or resistance to a range of insults: inflammatory, vascular (THBS1, ANXA1, ARRDC3-AS1 $\left.{ }^{34}\right)$ and neurodegenerative (C15orf53, ZIC4, ANXA1), and have been associated with pediatric and adult psychiatric conditions (THBS1). At a molecular level, the wnt/ $\beta$-catenin, TGF- $\beta$ and sonic hedgehog pathways are strongly implicated. Gene-set-enrichment analyses revealed biological processes related to brain morphology and neuronal development.

There is a wealth of information in the supplementary tables that can be mined for a better understanding of brain development, connectivity, function and pathology. We highlight this potential by discussing in additional detail, the possible significance of 6 illustrative loci, 5 of 
bioRxiv preprint first posted online Sep. 9, 2018; doi: http://dx.doi.org/10.1101/409649. The copyright holder for this preprint (which was not peer-reviewed) is the author/funder, who has granted bioRxiv a license to display the preprint in perpetuity.

It is made available under a CC-BY-NC-ND 4.0 International license.

which, at 15q14, 14q23.1, 6q22.32, 17q21.31 and 3q24, associate with multiple brain regions at low p-values, while the locus at 8q24.12 identifies a plausible exonic variant.

The Chr15q14 locus was associated with cortical thickness, surface area and volumes in the postcentral gyrus as well as with surface area or volume across 6 other regions in the frontal and parietal lobes. Lead SNPs at this locus were either intergenic between C15orf53 and C15orf54, or intergenic between C15orf54 and THBS1 (Thrombospondin-1). C15orf53 has been associated with an autosomal recessive form of spastic paraplegia showing intellectual disability and thinning of the corpus callosum (hereditary spastic paraparesis 11 , or Nakamura Osame syndrome). Variants of THBS1 were reported to be related to autism ${ }^{35}$ and schizophrenia $^{36}$. The protein product of THBS1 is involved in astrocyte induced synaptogenesis $^{37}$, and regulates chain migration of interneuron precursors migrating in the postnatal radial migration stream to the olfactory bulb ${ }^{38}$. Moreover, THBS1 is an activator of TGF $\beta$ signaling, and an inhibitor of pro-angiogenic nitric oxide signaling which plays a role in several cancers and immune-inflammatory conditions.

Variants at Chr14q23.1 were associated with cortical surface area and volume of all regions in the occipital lobe, as well as with thickness, surface area and volume of the middle temporal cortex, banks of the superior temporal sulcus, fusiform, supramarginal and precuneus regions, areas associated with discrimination and recognition of language or visual form. These variants are either intergenic between KIAA0586, the product of which is a conserved centrosomal protein essential for ciliogenesis, sonic hedgehog signaling and intracellular organization, and DACT1, the product of which is a target for SIRT1 and acts on the wnt/ $\beta$-catenin pathway. KIAA0586 has been associated with Joubert syndrome, another condition associated with abnormal cerebellar development. Other variants are intergenic between $D A C T 1$ and $D A A M 1$ or intronic in $D A A M 1$. DAAM1 has been associated with occipital lobe volume in a previous GWAS. 
bioRxiv preprint first posted online Sep. 9, 2018; doi: http://dx.doi.org/10.1101/409649. The copyright holder for this preprint (which was not peer-reviewed) is the author/funder, who has granted bioRxiv a license to display the preprint in perpetuity.

It is made available under a CC-BY-NC-ND 4.0 International license.

Locus 6q22.32 contains various SNPs associated with cortical surface area and volume globally, and also within some frontal, temporal and occipital regions. The SNPs are intergenic between RSPO3 and CENPW. RSPO3 and CENPW have been previously associated with intracranial ${ }^{39,40}$ and occipital lobe volumes. RSPO3 is an activator of the canonical Wnt signaling pathway and a regulator of angiogenesis.

Chr17q21.31 variants were associated with global cortical surface area and volume and with regions in temporal lobe. These variants are intronic in the genes PLEKHM1, CRHR1, NSF and WNT3. In previous GWAS analyses, these genes have been associated with general cognitive function ${ }^{41}$ and neuroticism ${ }^{42,43}$. CRHR1, NSF and WNT3 were additionally associated with Parkinson's disease ${ }^{44-48}$ and intracranial volume $\mathrm{s}^{39,40,49}$. The NSF gene also plays a role in Neuronal Intranuclear Inclusion Disease ${ }^{50}$ and $C R H R 1$ is involved in anxiety and depressive disorders ${ }^{51}$. This chromosomal region also contains the MAPT gene, which plays a role in Alzheimer's disease, Parkinson's disease, and frontotemporal dementia ${ }^{52,53}$. The protein product of the gene ZIC4 is a $\mathrm{C} 2 \mathrm{H} 2$ zinc finger transcription factor that has an intraneuronal, non-synaptic expression and auto-antibodies to this protein have been associated with subacute sensory neuronopathy, limbic encephalitis and seizures in patients with breast, small cell lung or ovarian cancers. ZIC4 null mice have abnormal development of the visual pathway ${ }^{54}$ and heterozygous deletion of the gene has also been associated with a congenital cerebellar (Dandy-Walker) malformation ${ }^{55}$, thus implicating it widely in brain development as well as in neurodegeneration. $C 2 \mathrm{H} 2 \mathrm{ZF}$ transcription factors are the most widely expressed transcription factors in eukaryotes and show associations with responses to abiotic (environmental) stressors. Another transcription factor, FOXC1, also associated with Dandy-Walker syndrome has been previously shown to be associated with risk of all types of ischemic stroke and with stroke severity. Thus, ZIC4 might be a biological target worth pursuing to ameliorate neurodegenerative disorders. 
We found an exonic SNP within the gene ENPP2 (Autotaxin) at 8q24.12 to be associated with insular cortical volume. This gene is differentially expressed in the frontal cortex of Alzheimer patients ${ }^{56}$ and in mouse models of Alzheimer disease such as the senescenceaccelerated mouse prone 8 strain (SAMP8) mouse. Autotaxin is a dual-function ectoenzyme, which is the primary source of the signaling lipid, lysophosphatidic acid. Besides Alzheimer disease, changes in autotaxin/lysophosphatidic acid signaling have also been shown in diverse brain related conditions such as intractable pain, pruritus, glioblastoma, multiple sclerosis and schizophrenia. In the SAMP8 mouse, improvements in cognition noted after administration of LW-AFC, a putative Alzheimer remedy derived from the traditional Chinese medicinal prescription 'Liuwei Dihuang' decoction, are correlated with restored expression of four genes in the hippocampus, one of which is ENPP2.

Among the other genetic regions identified, many have been linked to neurological and psychiatric disorders, cognitive functioning, cortical development and cerebral structure (detailed listing in Table S36).

Heritability estimates are, as expected, generally higher in the family-based Austrian Stroke Prevention-Family study (ASPS-Fam) than in the Rotterdam Study (RS) for CTh (average $\left.\mathrm{h}^{2}{ }_{\mathrm{ASPS}-\mathrm{Fam}}=0.52 ; \mathrm{h}^{2}{ }_{\mathrm{RS}}=0.26\right), \mathrm{CSA}(0.62$ and 0.30$)$ and $\mathrm{CV}(0.57$ and 0.23$)$. This discrepancy is explained by the different heritability estimation methods: pedigree-based heritability in ASPS-Fam versus heritability based on common SNPs that are in LD with causal variants ${ }^{57}$ in RS.

Average heritability over regions is also higher for surface area and volume, than for thickness. The observed greater heritability of CSA compared to CTh is consistent with the previously articulated hypothesis, albeit based on much smaller numbers, that CSA is developmentally determined to a greater extent with smaller subsequent decline after young 
adulthood, whereas CTh changes over the lifespan as aging, neurodegeneration and vascular injuries accrue $\mathrm{e}^{1,3}$. It is also interesting that brain regions more susceptible to early amyloid deposition (e.g. superior temporal cortex, precuneus) have a higher heritability.

We found no or weak genetic correlation between CTh and CSA, globally and regionally, and no common lead SNPs, which indicates that these two morphological measures are genetically independent, a finding consistent with prior reports ${ }^{25,26}$. In contrast, we found strong genetic correlation between CSA and CV and identified common lead SNPs for CSA and CV globally, and in 12 cortical regions. Similar findings have been reported in a previous publication $^{26}$. The genetic correlation between CTh and CV ranged between 0.09 and 0.77 , implying a common genetic background in some regions (such as the primary sensory postcentral and lingual cortices), but not in others. For CTh, we observed genetic correlations between multiple regions within each of the lobes, whereas for CSA and CV we found genetic correlations mainly between different regions of the occipital lobe. Chen et $\mathrm{al}^{58}$ have also reported strong genetic correlation for CSA within the occipital lobe. There were also a few genetic correlations observed for regions from different lobes, suggesting similarities in cortical development transcended traditional lobar boundaries.

A limitation of our study is the heterogeneity of the MR phenotypes between cohorts due to different scanners, field strengths, MR protocols and MRI analysis software. Therefore, association results were combined using a sample-size weighted meta-analysis which does not provide overall effect estimates. Moreover, our sample comprises of mainly European ancestry, limiting the generalizability to other ethnicities. Strengths of our study are the population-based design, the large age range of our sample (12 - 90 years), use of three cortical measures as phenotypes of cortical morphometry, and the replication of our CTh and CSA findings in a large and independent cohort. In conclusion, we identified patterns of 
bioRxiv preprint first posted online Sep. 9, 2018; doi: http://dx.doi.org/10.1101/409649. The copyright holder for this preprint (which was not peer-reviewed) is the author/funder, who has granted bioRxiv a license to display the preprint in perpetuity. It is made available under a CC-BY-NC-ND 4.0 International license.

heritability and genetic associations with various global and regional cortical measures, as well as overlap of MRI cortical measures with genetic traits and diseases that provide new insights into cortical development, morphology and possible mechanisms of disease susceptibility. 


\section{Methods}

\section{Study Population}

The sample of this study consist of up to 22,824 participants from 20 population-based cohort studies collaborating in the Cohorts of Heart and Aging Research in Genomic Epidemiology $(\mathrm{CHARGE})$ consortium ${ }^{59}$ and the UK Biobank $(\mathrm{UKBB})^{60}$. All the individuals were strokeand dementia free, aged between 12 and 90 years, and of European ancestry, except for ARIC AA with African ancestry. Table S1 provides population characteristics of each cohort and Supplementary Section 1 provides a short description of each study. Each study secured approval from institutional review boards or equivalent organizations, and all participants provided written informed consent. Our results were replicated using summary GWAS findings of 22,635 individuals from the Enhancing Neuroimaging Genetics through Metaanalysis (ENIGMA) consortium ${ }^{31}$.

\section{Genotyping and Imputation}

Genotyping was conducted using various commercially available genotyping arrays across the study cohorts. Prior to imputation, extensive quality control was performed in each cohort. Genotype data were imputed to the 1000 Genomes reference panel ${ }^{61}$ (mainly phase 1 , version 3) using validated software. Details on genotyping, quality control and imputation can be found in Table S2.

\section{Phenotype Definition}

This study investigated CTh, CSA and CV globally in the whole cortex and in 34 cortical regions. Global and regional CTh was defined as the mean thickness of the left and the right hemisphere in millimeter (mm). Global CSA was defined as the total surface area of the left 
and the right hemisphere in $\mathrm{mm}^{2}$, while regional CSA was defined as the mean surface area of the left and the right hemisphere in $\mathrm{mm}^{2}$. Global and regional $\mathrm{CV}$ was defined as the mean volume of the left and the right hemisphere in $\mathrm{mm}^{3}$. The 34 cortical regions are listed in Table S3. High resolution brain magnetic resonance imaging (MRI) data was obtained in each cohort using a range of MRI scanners, field strengths and protocols. CTh, CSA and CV were generated using the Freesurfer software package ${ }^{62,63}$ in all cohorts except for FHSucd, where an in-house segmentation method was used. MRI protocols of each cohort can be found in Table S4 and descriptive statistics of CTh, CSA and CV can be found in Tables S5, S6 and S7.

\section{Genome-wide associations, meta-analysis, replication and annotation}

Based on a predefined analysis plan, each study fitted linear regression models to determine the association between global and regional CTh, CSA and CV and allele dosages of single nucleotide polymorphisms (SNPs). Additive genetic effects were assumed and the models were adjusted for sex, age, age ${ }^{2}$, and if needed for study site and for principal components to correct for population stratification. Cohorts including related individuals calculated linear mixed models to account for family structure. Details on association software and covariates for each cohort are shown in Table S2. Models investigating regional CTh, CSA and CV were additionally adjusted for global CTh, global CSA and global CV, respectively. Quality control of the summary statistics shared by each cohort was performed using EasyQC ${ }^{64}$. Genetic variants with a minor allele frequency $(\mathrm{MAF})<0.05$, low imputation quality $\left(\mathrm{R}^{2}<0.4\right)$, and which were available in less than 10,000 individuals were removed from the analyses. Details on quality control are provided in Supplementary Section 2.

We then used METAL ${ }^{65}$ to perform meta-analyses using the $z$-scores method, based on $p$ values, sample size and direction of effect, with genomic control correction. We performed 10,000 permutation tests based on cortical measurements from Rotterdam Study to estimate 
bioRxiv preprint first posted online Sep. 9, 2018; doi: http://dx.doi.org/10.1101/409649. The copyright holder for this preprint (which was not peer-reviewed) is the author/funder, who has granted bioRxiv a license to display the preprint in perpetuity. It is made available under a CC-BY-NC-ND 4.0 International license.

the number of independent tests. Based on the permutation test results, the genome-wide significance threshold was set a priori at $1.09 \times 10^{-9}\left(=5 \times 10^{-8} / 46\right)$. We used the clumping function in PLINK ${ }^{66}$ (linkage disequilibrium (LD) threshold: 0.2 , distance: $300 \mathrm{~kb}$ ) to identify the most significant SNP in each LD block.

For replication of our genome-wide significant CTh and CSA associations, we used GWAS meta-analysis results from the ENIGMA consortium ${ }^{31}$ for all SNPs that were associated at a $\mathrm{p}$-value $<5 \times 10^{-8}$ and performed a pooled meta-analysis. The $\mathrm{p}$-value threshold for replication was set to $3.1 \times 10^{-4}$ (nominal significance threshold (0.05) divided by total number of lead SNPs (160)). CV was not available in the ENIGMA results. The NHGRI-EBI Catalog of published GWAS ${ }^{67}$ was searched for previous SNP-trait associations at a p-value of $5 \times 10^{-8}$ of lead SNPs.

Regional association plots were generated with LocusZoom ${ }^{68}$, and the chromosomal ideogram with PHENOGRAM (http://visualization.ritchielab.org/phenograms/plot). Annotation of genome-wide significant variants was performed using the ANNOVAR software package $^{69}$ and the FUMA web application ${ }^{70}$. FUMA eQTL mapping uses information from three data repositories (GTEx, Blood eQTL browser, and BIOS QTL browser) and maps SNPs to genes based on a significant eQTL association. We used a false discovery rate threshold (FDR) of 0.05 divided by number of tests (46) to define significant eQTL associations. Gene-based analyses, to combine the effects of SNPs assigned to a gene, and gene set analyses, to find out if genes assigned to significant SNPs were involved in biological pathways, were performed using MAGMA ${ }^{71}$ as implemented in FUMA. The significance threshold was set to $5.87 \times 10^{-8}$ for gene-based analyses (FDR threshold (0.05) divided by number of genes $(18,522)$ and number of independent tests $(46))$ and to $1.02 \times 10^{-7}$ for the gene-set analyses (FDR threshold (0.05) divided by the number of gene sets $(10,651)$ and by the number of independent tests (46)). Additionally, FUMA was used to investigate a 
significant chromatin interaction between a genomic region in a risk locus and promoter regions of genes (250 bp upstream and 500 bp downstream of a TSS). We used an FDR of $1 \times 10^{-6}$ to define significant interactions.

We investigated cis $(<1 \mathrm{Mb})$ and trans $(>1 \mathrm{MB}$ or on a different chromosome) expression quantitative trait loci (eQTL) for genome-wide significant SNPs in 724 post-mortem brains from the Religious Order Study and the Rush Memory and Aging Project (ROSMAP) ${ }^{72,73}$ stored in the AMP-AD database. The samples were collected from the gray matter of the dorsolateral prefrontal cortex. The significance threshold was set to 0.001 (FDR threshold (0.05) divided by the number of independent tests (46)).

For additional pathway analyses of genes that were mapped to independent lead SNPs by FUMA, we searched the InnateDB database ${ }^{74}$. The STRING database ${ }^{75}$ was used for visualizing protein-protein interactions. Only those protein subnetworks with five or more nodes are shown.

\section{Heritability}

Additive genetic heritability $\left(\mathrm{h}^{2}\right)$ of $\mathrm{CTh}, \mathrm{CSA}$ and $\mathrm{CV}$ was estimated in two studies: the Austrian Stroke Prevention Family Study (ASPS-Fam; n=365) and the Rotterdam Study (RS, $\mathrm{n}=4472$ ). In the population based family study ASPS-Fam, the ratio of the genotypic variance to the phenotypic variance was calculated using variance components models in SOLAR ${ }^{76}$. In case of non-normalty, phenotype data were inverse-normal transformed. In RS, SNP-based heritability was computed with GCTA ${ }^{77,78}$. These heritability analyses were adjusted for age and sex.

Heritability and partitioned heritability based on GWAS summary statistics was calculated from GWAS summary statistics using LD score regression (LDSC) implemented in the ldsc tool (https://github.com/bulik/ldsc). Partitioned heritability analysis splits genome-wide SNP 
heritability into 53 functional annotation classes (e.g. coding, 3' UTR, promoter, transcription factor binding sites, conserved regions etc.) and additionally to 10 cell-type specific classes (e.g. central nervous system, cardiovascular, liver, skeletal muscle etc.) as defined by Finucane et al. ${ }^{79}$ to estimate their contributions to heritability. The significance threshold was set to $2.05 \times 10^{-5}(0.05 /$ number of functional annotation classes (53) / number of independent tests (46)) for heritability partitioned on functional annotation classes and $2.05<10^{-6}(0.05 /$ number of functional annotation classes (53) / number of cell types (10) / number of independent tests (46)) for heritability partitioned on annotation classes and cell types.

\section{Genetic correlation}

LDSR genetic correlation ${ }^{80}$ between CTh, CSA and CV was estimated globally and within each cortical region. The significance threshold was set to $7.35 \times 10-4$ (nominal threshold (0.05) divided by number of regions (34) and by number of correlations (CSA and CV, CSA and CTh). Genetic correlation was also estimated between all 34 cortical regions for CTh, CSA and CV, with the significance threshold set to $8.91 \times 10-5$ (nominal threshold $(0.05)$ divided by number of regions (34) times the number of regions -1 (33) divided by 2 (half of the matrix). Additionally, the amount of genetic correlation was quantified between CTh, CSA and CV and physical traits (height, BMI), neurological and psychiatric diseases (e.g. Alzheimer's disease, Parkinson's disease), cognitive traits and MRI volumes (p-value threshold (0.05/46/number of GWAS traits). As recommended by the ldst tool developers, only HapMap3 variants were included in these analyses, as these tend to be well-imputed across cohorts. 
1 Storsve, A. B. et al. Differential longitudinal changes in cortical thickness, surface area and volume across the adult life span: regions of accelerating and decelerating change. The Journal of neuroscience : the official journal of the Society for Neuroscience 34, 8488-8498, doi:10.1523/JNEUROSCI.0391-14.2014 (2014).

2 Hogstrom, L. J., Westlye, L. T., Walhovd, K. B. \& Fjell, A. M. The structure of the cerebral cortex across adult life: age-related patterns of surface area, thickness, and gyrification. Cerebral cortex 23, 2521-2530, doi:10.1093/cercor/bhs231 (2013).

3 Fjell, A. M. et al. Development and aging of cortical thickness correspond to genetic organization patterns. Proceedings of the National Academy of Sciences of the United States of America 112, 15462-15467, doi:10.1073/pnas.1508831112 (2015).

4 Vuoksimaa, E. et al. The Genetic Association Between Neocortical Volume and General Cognitive Ability Is Driven by Global Surface Area Rather Than Thickness. Cerebral cortex 25, 2127-2137, doi:10.1093/cercor/bhu018 (2015).

5 Vuoksimaa, E. et al. Is bigger always better? The importance of cortical configuration with respect to cognitive ability. Neurolmage 129, 356-366, doi:10.1016/j.neuroimage.2016.01.049 (2016).

6 Lerch, J. P. et al. Focal decline of cortical thickness in Alzheimer's disease identified by computational neuroanatomy. Cerebral cortex 15, 995-1001, doi:10.1093/cercor/bhh200 (2005).

7 Lerch, J. P. et al. Automated cortical thickness measurements from MRI can accurately separate Alzheimer's patients from normal elderly controls. Neurobiology of aging 29, 23-30, doi:10.1016/j.neurobiolaging.2006.09.013 (2008).

8 Uribe, C. et al. Patterns of cortical thinning in nondemented Parkinson's disease patients. Movement disorders : official journal of the Movement Disorder Society 31, 699-708, doi:10.1002/mds.26590 (2016).

9 Jubault, T. et al. Patterns of cortical thickness and surface area in early Parkinson's disease. Neurolmage 55, 462-467, doi:10.1016/j.neuroimage.2010.12.043 (2011).

10 Narayana, P. A. et al. Regional cortical thickness in relapsing remitting multiple sclerosis: A multi-center study. Neurolmage. Clinical 2, 120-131, doi:10.1016/j.nicl.2012.11.009 (2012).

11 Steenwijk, M. D. et al. Cortical atrophy patterns in multiple sclerosis are non-random and clinically relevant. Brain : a journal of neurology 139, 115-126, doi:10.1093/brain/awv337 (2016).

12 Rimol, L. M. et al. Cortical volume, surface area, and thickness in schizophrenia and bipolar disorder. Biological psychiatry 71, 552-560, doi:10.1016/j.biopsych.2011.11.026 (2012).

13 van Haren, N. E. et al. Changes in cortical thickness during the course of illness in schizophrenia. Archives of general psychiatry 68, 871-880, doi:10.1001/archgenpsychiatry.2011.88 (2011).

14 Hibar, D. P. et al. Cortical abnormalities in bipolar disorder: an MRI analysis of 6503 individuals from the ENIGMA Bipolar Disorder Working Group. Molecular psychiatry 23, 932-942, doi:10.1038/mp.2017.73 (2018).

15 Niu, M. et al. Common and Specific Abnormalities in Cortical Thickness in Patients with Major Depressive and Bipolar Disorders. EBioMedicine 16, 162-171, doi:10.1016/j.ebiom.2017.01.010 (2017).

16 Schmaal, L. et al. Cortical abnormalities in adults and adolescents with major depression based on brain scans from 20 cohorts worldwide in the ENIGMA Major Depressive Disorder Working Group. Molecular psychiatry 22, 900-909, doi:10.1038/mp.2016.60 (2017).

17 Ecker, C. et al. Brain surface anatomy in adults with autism: the relationship between surface area, cortical thickness, and autistic symptoms. JAMA psychiatry 70, 59-70, doi:10.1001/jamapsychiatry.2013.265 (2013).

18 van Rooij, D. et al. Cortical and Subcortical Brain Morphometry Differences Between Patients With Autism Spectrum Disorder and Healthy Individuals Across the Lifespan: Results From the 
bioRxiv preprint first posted online Sep. 9, 2018; doi: http://dx.doi.org/10.1101/409649. The copyright holder for this preprint (which was not peer-reviewed) is the author/funder, who has granted bioRxiv a license to display the preprint in perpetuity.

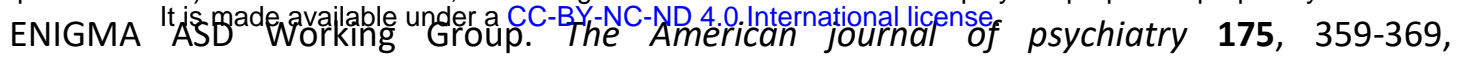
doi:10.1176/appi.ajp.2017.17010100 (2018).

19 Mountcastle, V. B. The columnar organization of the neocortex. Brain : a journal of neurology 120 ( Pt 4), 701-722 (1997).

20 Rakic, P. A small step for the cell, a giant leap for mankind: a hypothesis of neocortical expansion during evolution. Trends in neurosciences 18, 383-388 (1995).

21 Rakic, P. Evolution of the neocortex: a perspective from developmental biology. Nature reviews. Neuroscience 10, 724-735, doi:10.1038/nrn2719 (2009).

22 Rimol, L. M. et al. Cortical thickness is influenced by regionally specific genetic factors. Biological psychiatry 67, 493-499, doi:10.1016/j.biopsych.2009.09.032 (2010).

23 Chen, C. H. et al. Hierarchical genetic organization of human cortical surface area. Science 335, 1634-1636, doi:10.1126/science.1215330 (2012).

24 Eyler, L. T. et al. Genetic and environmental contributions to regional cortical surface area in humans: a magnetic resonance imaging twin study. Cerebral cortex 21, 2313-2321, doi:10.1093/cercor/bhr013 (2011).

25 Panizzon, M. S. et al. Distinct genetic influences on cortical surface area and cortical thickness. Cerebral cortex 19, 2728-2735, doi:10.1093/cercor/bhp026 (2009).

26 Winkler, A. M. et al. Cortical thickness or grey matter volume? The importance of selecting the phenotype for imaging genetics studies. Neurolmage 53, 1135-1146, doi:10.1016/j.neuroimage.2009.12.028 (2010).

27 Blokland, G. A., de Zubicaray, G. I., McMahon, K. L. \& Wright, M. J. Genetic and environmental influences on neuroimaging phenotypes: a meta-analytical perspective on twin imaging studies. Twin research and human genetics : the official journal of the International Society for Twin Studies 15, 351-371, doi:10.1017/thg.2012.11 (2012).

28 Kremen, W. S. et al. Genetic and environmental influences on the size of specific brain regions in midlife: the VETSA MRI study. Neurolmage 49, 1213-1223, doi:10.1016/j.neuroimage.2009.09.043 (2010).

29 Joshi, A. A. et al. The contribution of genes to cortical thickness and volume. Neuroreport 22, 101-105, doi:10.1097/WNR.0b013e3283424c84 (2011).

30 Wen, W. et al. Distinct Genetic Influences on Cortical and Subcortical Brain Structures. Scientific reports 6, 32760, doi:10.1038/srep32760 (2016).

31 Grasby, K. L. et al. The genetic architecture of the human cerebral cortex. BioRxiv (2018).

32 Elliott, L. T. et al. Genome-wide association studies of brain imaging phenotypes in UK Biobank. Nature 562, 210-216, doi:10.1038/s41586-018-0571-7 (2018).

33 Hibar, D. P. et al. Novel genetic loci associated with hippocampal volume. Nature communications 8, 13624, doi:10.1038/ncomms13624 (2017).

34 Irvin, M. R. et al. Genome-wide meta-analysis of SNP-by9-ACEI/ARB and SNP-by-thiazide diuretic and effect on serum potassium in cohorts of European and African ancestry. The pharmacogenomics journal, doi:10.1038/s41397-018-0021-9 (2018).

35 Lu, L. et al. Common and rare variants of the THBS1 gene associated with the risk for autism. Psychiatric genetics 24, 235-240, doi:10.1097/YPG.0000000000000054 (2014).

36 Park, H. J., Kim, S. K., Kim, J. W., Kang, W. S. \& Chung, J. H. Association of thrombospondin 1 gene with schizophrenia in Korean population. Molecular biology reports 39, 6875-6880, doi:10.1007/s11033-012-1513-3 (2012).

37 Christopherson, K. S. et al. Thrombospondins are astrocyte-secreted proteins that promote CNS synaptogenesis. Cell 120, 421-433, doi:10.1016/j.cell.2004.12.020 (2005).

38 Blake, S. M. et al. Thrombospondin-1 binds to ApoER2 and VLDL receptor and functions in postnatal neuronal migration. The EMBO journal 27, 3069-3080, doi:10.1038/emboj.2008.223 (2008).

39 Ikram, M. A. et al. Common variants at $6 \mathrm{q} 22$ and $17 \mathrm{q} 21$ are associated with intracranial volume. Nature genetics 44, 539-544, doi:10.1038/ng.2245 (2012).

40 Adams, H. H. et al. Novel genetic loci underlying human intracranial volume identified through genome-wide association. Nature neuroscience 19, 1569-1582, doi:10.1038/nn.4398 (2016). 
bioRxiv preprint first posted online Sep. 9, 2018; doi: http://dx.doi.org/10.1101/409649. The copyright holder for this preprint (which was not peer-reviewed) is the author/funder, who has granted bioRxiv a license to display the preprint in perpetuity.

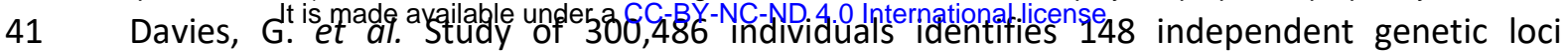
influencing general cognitive function. Nat Commun 9, 2098, doi:10.1038/s41467-018-04362$x(2018)$.

42 Luciano, M. et al. Association analysis in over 329,000 individuals identifies 116 independent variants influencing neuroticism. Nature genetics 50, 6-11, doi:10.1038/s41588-017-0013-8 (2018).

43 Smith, D. J. et al. Genome-wide analysis of over 106000 individuals identifies 9 neuroticismassociated loci. Molecular psychiatry 21, 749-757, doi:10.1038/mp.2016.49 (2016).

44 Chang, D. et al. A meta-analysis of genome-wide association studies identifies 17 new Parkinson's disease risk loci. Nature genetics 49, 1511-1516, doi:10.1038/ng.3955 (2017).

45 Pickrell, J. K. et al. Detection and interpretation of shared genetic influences on 42 human traits. Nature genetics 48, 709-717, doi:10.1038/ng.3570 (2016).

46 International Parkinson Disease Genomics, C. et al. Imputation of sequence variants for identification of genetic risks for Parkinson's disease: a meta-analysis of genome-wide association studies. Lancet 377, 641-649, doi:10.1016/S0140-6736(10)62345-8 (2011).

47 Simon-Sanchez, J. et al. Genome-wide association study reveals genetic risk underlying Parkinson's disease. Nature genetics 41, 1308-1312, doi:10.1038/ng.487 (2009).

48 Pankratz, N. et al. Meta-analysis of Parkinson's disease: identification of a novel locus, RIT2. Annals of neurology 71, 370-384, doi:10.1002/ana.22687 (2012).

49 Hibar, D. P. et al. Common genetic variants influence human subcortical brain structures. Nature 520, 224-229, doi:10.1038/nature14101 (2015).

50 Pountney, D. L., Raftery, M. J., Chegini, F., Blumbergs, P. C. \& Gai, W. P. NSF, Unc-18-1, dynamin-1 and HSP9O are inclusion body components in neuronal intranuclear inclusion disease identified by anti-SUMO-1-immunocapture. Acta neuropathologica 116, 603-614, doi:10.1007/s00401-008-0437-4 (2008).

51 Muller, M. B. \& Wurst, W. Getting closer to affective disorders: the role of CRH receptor systems. Trends in molecular medicine 10, 409-415, doi:10.1016/j.molmed.2004.06.007 (2004).

52 Desikan, R. S. et al. Genetic overlap between Alzheimer's disease and Parkinson's disease at the MAPT locus. Molecular psychiatry 20, 1588-1595, doi:10.1038/mp.2015.6 (2015).

53 Spillantini, M. G. \& Goedert, M. Tau pathology and neurodegeneration. The Lancet. Neurology 12, 609-622, doi:10.1016/S1474-4422(13)70090-5 (2013).

54 Horng, S. et al. Differential gene expression in the developing lateral geniculate nucleus and medial geniculate nucleus reveals novel roles for Zic4 and Foxp2 in visual and auditory pathway development. The Journal of neuroscience : the official journal of the Society for Neuroscience 29, 13672-13683, doi:10.1523/JNEUROSCI.2127-09.2009 (2009).

55 Grinberg, I. et al. Heterozygous deletion of the linked genes ZIC1 and ZIC4 is involved in DandyWalker malformation. Nature genetics 36, 1053-1055, doi:10.1038/ng1420 (2004).

56 Umemura, K. et al. Autotaxin expression is enhanced in frontal cortex of Alzheimer-type dementia patients. Neuroscience letters 400, 97-100, doi:10.1016/j.neulet.2006.02.008 (2006).

57 Wray, N. R. et al. Pitfalls of predicting complex traits from SNPs. Nature reviews. Genetics 14, 507-515, doi:10.1038/nrg3457 (2013).

58 Chen, C. H. et al. Genetic influences on cortical regionalization in the human brain. Neuron 72, 537-544, doi:10.1016/j.neuron.2011.08.021 (2011).

59 Psaty, B. M. et al. Cohorts for Heart and Aging Research in Genomic Epidemiology (CHARGE) Consortium: Design of prospective meta-analyses of genome-wide association studies from 5 cohorts. Circulation. Cardiovascular genetics 2, 73-80, doi:10.1161/CIRCGENETICS.108.829747 (2009).

60 Sudlow, C. et al. UK biobank: an open access resource for identifying the causes of a wide range of complex diseases of middle and old age. PLOS medicine 12, e1001779, doi:10.1371/journal.pmed.1001779 (2015).

61 Clarke, L. et al. The 1000 Genomes Project: data management and community access. Nature methods 9, 459-462, doi:10.1038/nmeth.1974 (2012). 
bioRxiv preprint first posted online Sep. 9, 2018; doi: http://dx.doi.org/10.1101/409649. The copyright holder for this preprint (which was not peer-reviewed) is the author/funder, who has granted bioRxiv a license to display the preprint in perpetuity.

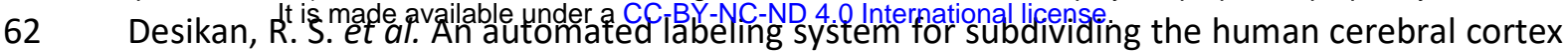
on MRI scans into gyral based regions of interest. Neurolmage 31, 968-980, doi:10.1016/j.neuroimage.2006.01.021 (2006).

63 Fischl, B. et al. Automatically parcellating the human cerebral cortex. Cerebral cortex 14, 1122 (2004).

64 Winkler, T. W. et al. Quality control and conduct of genome-wide association meta-analyses. Nature protocols 9, 1192-1212, doi:10.1038/nprot.2014.071 (2014).

65 Willer, C. J., Li, Y. \& Abecasis, G. R. METAL: fast and efficient meta-analysis of genomewide association scans. Bioinformatics 26, 2190-2191, doi:10.1093/bioinformatics/btq340 (2010).

66 Chang, C. C. et al. Second-generation PLINK: rising to the challenge of larger and richer datasets. GigaScience 4, 7, doi:10.1186/s13742-015-0047-8 (2015).

67 MacArthur, J. et al. The new NHGRI-EBI Catalog of published genome-wide association studies (GWAS Catalog). Nucleic acids research 45, D896-D901, doi:10.1093/nar/gkw1133 (2017).

68 Pruim, R. J. et al. LocusZoom: regional visualization of genome-wide association scan results. Bioinformatics 26, 2336-2337, doi:10.1093/bioinformatics/btq419 (2010).

69 Wang, K., Li, M. \& Hakonarson, H. ANNOVAR: functional annotation of genetic variants from high-throughput sequencing data. Nucleic acids research 38, e164, doi:10.1093/nar/gkq603 (2010).

70 Watanabe, K., Taskesen, E., van Bochoven, A. \& Posthuma, D. Functional mapping and annotation of genetic associations with FUMA. Nature communications 8, 1826, doi:10.1038/s41467-017-01261-5 (2017).

71 de Leeuw, C. A., Mooij, J. M., Heskes, T. \& Posthuma, D. MAGMA: generalized gene-set analysis of GWAS data. PLoS computational biology 11, e1004219, doi:10.1371/journal.pcbi.1004219 (2015).

72 Bennett, D. A., Schneider, J. A., Arvanitakis, Z. \& Wilson, R. S. Overview and findings from the religious orders study. Current Alzheimer research 9, 628-645 (2012).

73 Bennett, D. A. et al. Overview and findings from the rush Memory and Aging Project. Current Alzheimer research 9, 646-663 (2012).

74 Breuer, K. et al. InnateDB: systems biology of innate immunity and beyond--recent updates and continuing curation. Nucleic acids research 41, D1228-1233, doi:10.1093/nar/gks1147 (2013).

75 Szklarczyk, D. et al. The STRING database in 2017: quality-controlled protein-protein association networks, made broadly accessible. Nucleic acids research 45, D362-D368, doi:10.1093/nar/gkw937 (2017).

76 Almasy, L. \& Blangero, J. Multipoint quantitative-trait linkage analysis in general pedigrees. American journal of human genetics 62, 1198-1211, doi:10.1086/301844 (1998).

77 Yang, J., Lee, S. H., Goddard, M. E. \& Visscher, P. M. GCTA: a tool for genome-wide complex trait analysis. American journal of human genetics 88, 76-82, doi:10.1016/j.ajhg.2010.11.011 (2011).

78 Yang, J. et al. Common SNPs explain a large proportion of the heritability for human height. Nature genetics 42, 565-569, doi:10.1038/ng.608 (2010).

79 Finucane, H. K. et al. Partitioning heritability by functional annotation using genome-wide association summary statistics. Nature genetics 47, 1228-1235, doi:10.1038/ng.3404 (2015).

80 Bulik-Sullivan, B. et al. An atlas of genetic correlations across human diseases and traits. Nature genetics 47, 1236-1241, doi:10.1038/ng.3406 (2015). 
bioRxiv preprint first posted online Sep. 9, 2018; doi: http://dx.doi.org/10.1101/409649. The copyright holder for this preprint (which was not peer-reviewed) is the author/funder, who has granted bioRxiv a license to display the preprint in perpetuity. Acknowledgements

\section{CHARGE}

Infrastructure for the CHARGE Consortium is supported in part by the National Heart, Lung, and Blood Institute grant HL105756 and for the neuroCHARGE phenotype working group through the National Institute on Aging grant AG033193.

\section{Atherosclerosis Risk in Communities Study (ARIC)}

The Atherosclerosis Risk in Communities (ARIC) study is carried out as a collaborative study supported by the National Heart, Lung, and Blood Institute (NHLBI) contracts (HHSN268201100005C, HHSN268201100006C, HHSN268201100007C, HHSN268201100008C, HHSN268201100009C, HHSN268201100010C, HHSN268201100011C, and HHSN268201100012C). The authors thank the staff and participants of the ARIC study for their important contributions. Funding support for "Building on GWAS for NHLBI-diseases: the U.S. CHARGE consortium" was provided by the NIH through the American Recovery and Reinvestment Act of 2009 (ARRA) (5RC2HL102419). This project was also funded from R01-NS087541.

Austrian Stroke Prevention Family (ASPS) / Austrian Stroke Prevention Family Study (ASPS-Fam)

The authors thank the staff and the participants for their valuable contributions. We thank Birgit Reinhart for her long-term administrative commitment, Elfi Hofer for the technical assistance at creating the DNA bank, Ing. Johann Semmler and Anita Harb for DNA sequencing and DNA analyses by TaqMan assays and Irmgard Poelzl for supervising the quality management processes after ISO9001 at the biobanking and DNA analyses. The Medical University of Graz and the Steiermärkische Krankenanstaltengesellschaft support the databank of the ASPS/ASPS-Fam. The research reported in this article was funded by the Austrian Science Fund (FWF) grant numbers PI904, P20545-P05 and P13180 
bioRxiv preprint first posted online Sep. 9, 2018; doi: http://dx.doi.org/10.1101/409649. The copyright holder for this preprint (which was not peer-reviewed) is the author/funder, who has granted bioRxiv a license to display the preprint in perpetuity. and supported by the Austrian National Bank-ADnniversary Fund, 415435 and the Austrian Ministry of Science under the aegis of the EU Joint Programme-Neurodegenerative Disease Research (JPND)-www.jpnd.eu.

\section{Cardiovascular Health Study (CHS)}

Cardiovascular Health Study: This CHS research was supported by NHLBI contracts HHSN268201200036C, HHSN268200800007C, HHSN268201800001C, N01HC55222, N01HC85079, N01HC85080, N01HC85081, N01HC85082, N01HC85083, N01HC85086, N01HC15103, HHSN268200960009C; and NHLBI grants U01HL080295, R01HL087652, R01HL105756, R01HL103612, R01HL120393, and U01HL130114 with additional contribution from the National Institute of Neurological Disorders and Stroke (NINDS). Additional support was provided through R01AG023629, and R01AG033193 from the National Institute on Aging (NIA). A full list of principal CHS investigators and institutions can be found at CHS-NHLBI.org.

The provision of genotyping data was supported in part by the National Center for Advancing Translational Sciences, CTSI grant UL1TR001881, and the National Institute of Diabetes and Digestive and Kidney Disease Diabetes Research Center (DRC) grant DK063491 to the Southern California Diabetes Endocrinology Research Center.

The content is solely the responsibility of the authors and does not necessarily represent the official views of the National Institutes of Health.

\section{Erasmus Rucphen Family Study (ERF)}

Erasmus Rucphen Family (ERF) was supported by the Consortium for Systems Biology (NCSB), both within the framework of the Netherlands Genomics Initiative (NGI)/Netherlands Organisation for Scientific Research (NWO). ERF study as a part of EUROSPAN (European Special Populations Research Network) was supported by European 
bioRxiv preprint first posted online Sep. 9, 2018; doi: http://dx.doi.org/10.1101/409649. The copyright holder for this preprint (which was not peer-reviewed) is the author/funder, who has granted bioRxiv a license to display the preprint in perpetuity.

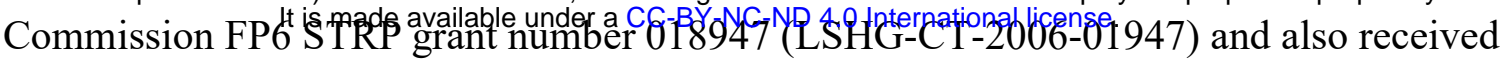

funding from the European Community's Seventh Framework Programme (FP7/2007-

2013)/grant agreement HEALTH-F4-2007-201413 by the European Commission under the programme "Quality of Life and Management of the Living Resources" of 5th Framework Programme (No. QLG2-CT-2002-01254) as well as FP7 project EUROHEADPAIN (nr 602633). High-throughput analysis of the ERF data was supported by joint grant from Netherlands Organisation for Scientific Research and the Russian Foundation for Basic Research (NWO-RFBR 047.017.043). High throughput metabolomics measurements of the ERF study has been supported by BBMRI-NL (Biobanking and Biomolecular Resources Research Infrastructure Netherlands).

\section{Framingham Heart Study (FHS)}

This work was supported by the National Heart, Lung and Blood Institute's Framingham Heart Study (Contract No. N01-HC-25195 and No. HHSN268201500001I) and its contract with Affymetrix, Inc. for genotyping services (Contract No. N02-HL-6-4278). A portion of this research utilized the Linux Cluster for Genetic Analysis (LinGA-II) funded by the Robert

Dawson Evans Endowment of the Department of Medicine at Boston University School of Medicine and Boston Medical Center. This study was also supported by grants from the National Institute of Aging (R01s AG033040, AG033193, AG054076, AG049607, AG008122, AG016495; and U01-AG049505) and the National Institute of Neurological Disorders and Stroke (R01-NS017950). We would like to thank the dedication of the Framingham Study participants, as well as the Framingham Study team, especially investigators and staff from the Neurology group, for their contributions to data collection. Dr. DeCarli is supported by the Alzheimer's Disease Center (P30 AG 010129). The views expressed in this manuscript are those of the authors and do not necessarily represent the views of the National Heart, Lung, and Blood Institute; the National Institutes of Health; or the U.S. Department of Health and Human Services. 
bioRxiv preprint first posted online Sep. 9, 2018; doi: http://dx.doi.org/10.1101/409649. The copyright holder for this preprint (which was not peer-reviewed) is the author/funder, who has granted bioRxiv a license to display the preprint in perpetuity. It is made available under a CC-BY-NC-ND 4.0 International license.

\section{Lothian Birth Cohort 1936 (LBC1936)}

This project is funded by the Age UK's Disconnected Mind programme (http://www.disconnectedmind.ed.ac.uk) and also by Research Into Ageing (Refs. 251 and 285). The whole genome association part of the study was funded by the Biotechnology and Biological Sciences Research Council (BBSRC; Ref. BB/F019394/1). Analysis of the brain images was funded by the Medical Research Council Grants G1001401 and 8200 and MR/M01311/1. The imaging was performed at the Brain Research Imaging Centre, The University of Edinburgh (http://www.bric.ed.ac.uk), a centre in the SINAPSE Collaboration (http://www.sinapse.ac.uk). The work was undertaken by The University of Edinburgh Centre for Cognitive Ageing and Cognitive Epidemiology (http://www.ccace.ed.ac.uk), part of the cross council Lifelong Health and Wellbeing Initiative (Ref. G0700704/84698). Funding from the BBSRC, Medical Research Council (MR/K026992/1) and Scottish Funding Council through the SINAPSE Collaboration is gratefully acknowledged.

We thank the LBC1936 participants and research team members. We also thank the nurses and staff at the Wellcome Trust Clinical Research Facility (http://www.wtcrf.ed.ac.uk), where subjects were tested and the genotyping was performed.

\section{LIFE-Adult}

LIFE-Adult is funded by the Leipzig Research Center for Civilization Diseases (LIFE). LIFE is an organizational unit affiliated to the Medical Faculty of the University of Leipzig. LIFE is funded by means of the European Union, by the European Regional Development Fund (ERDF) and by funds of the Free State of Saxony within the framework of the excellence initiative. This work was also funded by the Deutsche Forschungsgemeinschaft (Grant Number: CRC 1052 “Obesity mechanisms” project A1 to AV) and by the Max Planck Society. 
bioRxiv preprint first posted online Sep. 9, 2018; doi: http://dx.doi.org/10.1101/409649. The copyright holder for this preprint (which was not peer-reviewed) is the author/funder, who has granted bioRxiv a license to display the preprint in perpetuity.

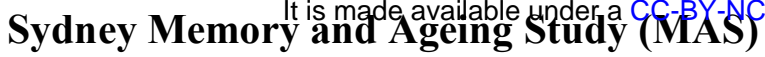

MAS is funded by the Australian National Health and Medical Research Council

(NHMRC)/Australian Research Council Strategic Award (Grant 401162), NHMRC Project grant 1405325 .

We would like to gratefully acknowledge and thank the Sydney MAS participants and supporters and the Sydney MAS Research Team.

\section{Older Australian Twin Study (OATS)}

OATS is funded by the Australian National Health and Medical Research Council (NHMRC)/Australian Research Council Strategic Award (Grant 401162), NHMRC Program Grants $(350833,568969,109308)$

We would like thank and gratefully acknowledge the OATS participants, their supporters and the OATS Research Team.

\section{Rotterdam Study (RSI, RSII, RSIII)}

The Rotterdam Study is funded by Erasmus Medical Center and Erasmus University, Rotterdam, Netherlands Organization for the Health Research and Development (ZonMw), the Research Institute for Diseases in the Elderly (RIDE), the Ministry of Education, Culture and Science, the Ministry for Health, Welfare and Sports, the European Commission (DG XII), and the Municipality of Rotterdam. The authors are grateful to the study participants, the staff from the Rotterdam Study and the participating general practitioners and pharmacists. The generation and management of GWAS genotype data for the Rotterdam Study (RS I, RS II, RS III) were executed by the Human Genotyping Facility of the Genetic Laboratory of the Department of Internal Medicine, Erasmus MC, Rotterdam, The Netherlands. The GWAS datasets are supported by the Netherlands Organisation of Scientific Research NWO Investments (nr. 175.010.2005.011, 911-03-012), the Genetic Laboratory of the Department of Internal Medicine, Erasmus MC, the Research Institute for Diseases in the 
bioRxiv preprint first posted online Sep. 9, 2018; doi: http://dx.doi.org/10.1101/409649. The copyright holder for this preprint (which was not peer-reviewed) is the author/funder, who has granted bioRxiv a license to display the preprint in perpetuity. Elderly (014-93-0is;

Organisation for Scientific Research (NWO) Netherlands Consortium for Healthy Aging (NCHA), project nr. 050-060-810. We thank Pascal Arp, Mila Jhamai, Marijn Verkerk, Lizbeth Herrera and Marjolein Peters, and Carolina Medina-Gomez, for their help in creating the GWAS database, and Karol Estrada, Yurii Aulchenko, and Carolina Medina-Gomez, for the creation and analysis of imputed data. This work has been performed as part of the CoSTREAM project (www.costream.eu) and ORACLE project, and has received funding from the European Union's Horizon 2020 research and innovation programme under grant agreement No 667375 and No 678543.

\section{Study of Health in Pomerania (SHIP) / Study of Health in Pomerania Trend (SHIP-}

\section{Trend)}

SHIP is part of the Community Medicine Research net of the University of Greifswald, Germany, which is funded by the Federal Ministry of Education and Research (grants no. 01ZZ9603, 01ZZ0103, and 01ZZ0403), the Ministry of Cultural Affairs as well as the Social Ministry of the Federal State of Mecklenburg-West Pomerania, and the network 'Greifswald Approach to Individualized Medicine (GANI_MED)' funded by the Federal Ministry of Education and Research (grant 03IS2061A). Genome-wide data have been supported by the Federal Ministry of Education and Research (grant no. 03ZIK012) and a joint grant from Siemens Healthineers, Erlangen, Germany and the Federal State of Mecklenburg- West Pomerania. Whole-body MR imaging was supported by a joint grant from Siemens Healthineers, Erlangen, Germany and the Federal State of Mecklenburg West Pomerania. The University of Greifswald is a member of the Caché Campus program of the InterSystems $\mathrm{GmbH}$. 
bioRxiv preprint first posted online Sep. 9, 2018; doi: http://dx.doi.org/10.1101/409649. The copyright holder for this preprint (which was not peer-reviewed) is the author/funder, who has granted bioRxiv a license to display the preprint in perpetuity.

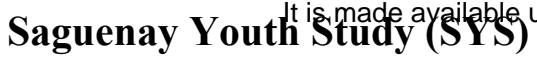

The Saguenay Youth Study has been funded by the Canadian Institutes of Health Research (TP, ZP), Heart and Stroke Foundation of Canada (ZP), and the Canadian Foundation for Innovation (ZP). We thank all families who took part in the Saguenay Youth Study. SYS is supported by the Canadian Institutes of Health Research: NET54015, NRF86678, TMH109788.

\section{Three-City Dijon (3C-Dijon)}

The Three City (3C) Study is conducted under a partnership agreement among the Institut National de la Santé et de la Recherche Médicale (INSERM), the University of Bordeaux, and Sanofi-Aventis. The Fondation pour la Recherche Médicale funded the preparation and initiation of the study. The $3 \mathrm{C}$ Study is also supported by the Caisse Nationale Maladie des Travailleurs Salariés, Direction Générale de la Santé, Mutuelle Générale de l'Education Nationale (MGEN), Institut de la Longévité, Conseils Régionaux of Aquitaine and Bourgogne, Fondation de France, and Ministry of Research-INSERM Programme "Cohortes et collections de données biologiques." Christophe Tzourio and Stéphanie Debette have received investigator-initiated research funding from the French National Research Agency (ANR) and from the Fondation Leducq. Stéphanie Debette is supported by a starting grant from the European Research Council (SEGWAY) and a grant from the Joint Programme of Neurodegenerative Disease research (BRIDGET), from the European Union's Horizon 2020 research and innovation programme under grant agreements No 643417 \& No 640643, and by the Initiative of Excellence of Bordeaux University. We thank Dr. Anne Boland (CNG) for her technical help in preparing the DNA samples for analyses. This work was supported by the National Foundation for Alzheimer's disease and related disorders, the Institut Pasteur de Lille, the labex DISTALZ and the Centre National de Génotypage. 
bioRxiv preprint first posted online Sep. 9, 2018; doi: http://dx.doi.org/10.1101/409649. The copyright holder for this preprint (which was not peer-reviewed) is the author/funder, who has granted bioRxiv a license to display the preprint in perpetuity.

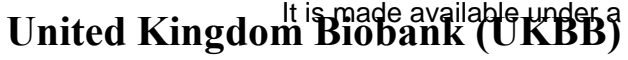

This research has been conducted using the UK Biobank Resource under Application Number “23509”.

\section{Vietnam Era Twin Study of Aging (VETSA)}

This work was supported by US National Institutes of Health grants AG018386, AG022381, AG022982, AG050595, AG018384, AG046413, AG047903，DA025109，DA023549, DA18673, HD050735, and U 54EB020403, and the VA San Diego Center of Excellence for Stress and Mental Health Healthcare System. The content is the responsibility of the authors and does not necessarily represent official views of the NIA, NIH, or VA. The Cooperative Studies Program of the U.S. Department of Veterans Affairs provided financial support for development and maintenance of the Vietnam Era Twin Registry. We would also like to acknowledge the continued cooperation and participation of the members of the VET Registry and their families.

\section{ENIGMA}

The study was supported in part by grant U54 EB020403 from the NIH Big Data to Knowledge (BD2K) Initiative, a cross-NIH partnership. Additional support was provided by R01MH116147, P41 EB015922, RF1AG051710, RF1 AG041915 (to P.T.), by P01 AG026572, R01 AG059874 and by R01 MH117601 (to N.J. and L.S.). S.E.M. was funded by an NHMRC Senior Research Fellowship (APP1103623). L.C.-C. was supported by a QIMR Berghofer Fellowship.

\section{ENIGMA consortium:}

Katrina L. Grasby (Psychiatric Genetics, QIMR Berghofer Medical Research Institute, Brisbane, Australia), Neda Jahanshad (Imaging Genetics Center, Mark and Mary Stevens Neuroimaging and Informatics Institute, Keck School of Medicine of USC, University of Southern California, Los Angeles, USA), Jodie N. Painter (Psychiatric Genetics, QIMR Berghofer Medical Research Institute, Brisbane, Australia), Lucía Colodro-Conde (Psychiatric 
bioRxiv preprint first posted online Sep. 9, 2018; doi: http://dx.doi.org/10.1101/409649. The copyright holder for this preprint (which was not peer-reviewed) is the author/funder, who has granted bioRxiv a license to display the preprint in perpetuity.

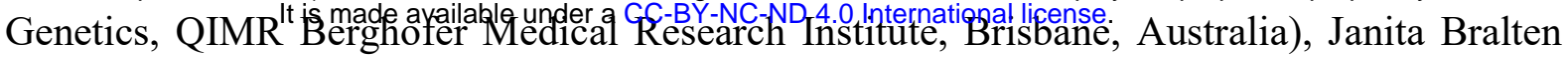
(Department of Human Genetics, Radboud university medical center, Nijmegen, The Netherlands), Derrek P. Hibar (Imaging Genetics Center, Mark and Mary Stevens Neuroimaging and Informatics Institute, Keck School of Medicine of USC, University of Southern California, Los Angeles, USA), Penelope A. Lind (Psychiatric Genetics, QIMR Berghofer Medical Research Institute, Brisbane, Australia), Fabrizio Pizzagalli (Imaging Genetics Center, Mark and Mary Stevens Neuroimaging and Informatics Institute, Keck School of Medicine of USC, University of Southern California, Los Angeles, USA), Christopher R.K. Ching (Imaging Genetics Center, Mark and Mary Stevens Neuroimaging and Informatics Institute, Keck School of Medicine of USC, University of Southern California, Los Angeles, USA), Mary Agnes B. McMahon (Imaging Genetics Center, Mark and Mary Stevens Neuroimaging and Informatics Institute, Keck School of Medicine of USC, University of Southern California, Los Angeles, USA), Natalia Shatokhina (Imaging Genetics Center, Mark and Mary Stevens Neuroimaging and Informatics Institute, Keck School of Medicine of USC, University of Southern California, Los Angeles, USA), Leo C.P. Zsembik (Department of Genetics \& UNC Neuroscience Center, University of North Carolina at Chapel HIll, Chapel Hill, USA), Ingrid Agartz (NORMENT - K.G. Jebsen Centre for Psychosis Research, Division of Mental Health and Addiction, NORMENT Oslo University Hospital, Oslo, Norway), Saud Alhusaini (Department of Molecular and Cellular Therapeutics, Royal College of Surgeons in Ireland, Dublin, Ireland), Marcio A.A. Almeida (Department of Human Genetics and South Texas Diabetes and Obesity Institute, Rio Grande Valley School of Medicine, University of Texas, Brownsville, USA), Dag Alnæs (NORMENT - K.G. Jebsen Centre for Psychosis Research, Division of Mental Health and Addiction, NORMENT Oslo University Hospital, Oslo, Norway), Inge K. Amlien (Centre for Lifespan Changes in Brain and Cognition, Department of Psychology, University of Oslo, Oslo, Norway), Micael Andersson (Department of Integrative Medical Biology, Umeå University, Umeå, Sweden), Tyler Ard (Laboratory of Neuro Imaging, Mark and Mary Stevens Neuroimaging and Informatics Institute, Keck School of Medicine, University of Southern California, Los Angeles, USA), Nicola J. Armstrong (Mathematics and Statistics, Murdoch University, Murdoch, Australia), Allison Ashley-Koch (Duke Molecular Physiology Institute, Duke University Medical Center, Durham, USA), Manon Bernard (The Hospital for Sick Children, University of Toronto, Toronto, Canada), Rachel M. Brouwer (Department of Psychiatry, Brain Center Rudolf Magnus, University Medical Center Utrecht, Utrecht University, Utrecht, The Netherlands), Elizabeth E.L. Buimer (Department of Psychiatry, Brain Center Rudolf Magnus, University Medical Center Utrecht, Utrecht University, Utrecht, The Netherlands), Robin Bülow (Institute of Diagnostic Radiology and Neuroradiology, University Medicine, Ernst-Moritz-Arndt University, Greifswald, Germany), Christian Bürger (Department of Psychiatry, University of Münster, Münster, Germany), Dara M. Cannon (Centre for Neuroimaging \& Cognitive Genomics, National University of Ireland Galway, Galway, Ireland), Mallar Chakravarty (Douglas Mental Health University Institute, McGill University, Montreal, Canada), Qiang Chen (Lieber Institute for Brain Development, Baltimore, USA), Joshua W. Cheung (Imaging Genetics Center, Mark and Mary Stevens Neuroimaging and Informatics Institute, Keck School of Medicine of USC, University of Southern California, Los Angeles, USA), Baptiste CouvyDuchesne (Institute for Molecular Bioscience, The University of Queensland, Brisbane, Australia), Anders M. Dale (Department of Neurosciences, University of California, San Diego, La Jolla, USA), Shareefa Dalvie (Department of Psychiatry and Mental Health, University of Cape Town, Cape Town, South Africa), Tânia K. de Araujo (Department of Medical Genetics, School of Medical Sciences, University of Campinas - UNICAMP, Campinas, Brazil), Greig I. de Zubicaray (Faculty of Health, Institute of Health and Biomedical Innovation, Queensland University of Technology, Brisbane, Australia), Sonja M.C. de Zwarte (Department of Psychiatry, Brain Center Rudolf Magnus, University Medical Center Utrecht, Utrecht University, Utrecht, The Netherlands), Anouk den Braber (Department of Biological Psychology, Vrije Universiteit Amsterdam, Amsterdam, The Netherlands), Nhat Trung Doan 
bioRxiv preprint first posted online Sep. 9, 2018; doi: http://dx.doi.org/10.1101/409649. The copyright holder for this preprint (which was not peer-reviewed) is the author/funder, who has granted bioRxiv a license to display the preprint in perpetuity.

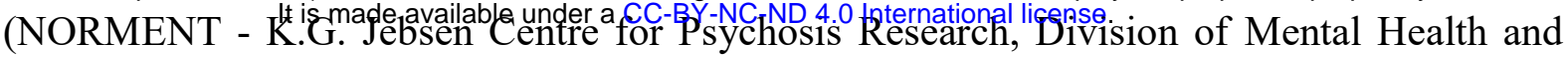
Addiction, NORMENT Oslo University Hospital, Oslo, Norway), Katharina Dohm (Department of Psychiatry, University of Münster, Münster, Germany), Stefan Ehrlich (Division of Psychological \& Social Medicine and Developmental Neurosciences, Technische Universität Dresden, Dresden, Germany), Hannah-Ruth Engelbrecht (Division of Human Genetics, Institute of Infectious Disease and Molecular Medicine, University of Cape Town, Cape Town, South Africa), Susanne Erk (Division of Mind and Brain Research, Department of Psychiatry and Psychotherapy, Campus Charité Mitte, Charité - Universitätsmedizin Berlin, Berlin, Germany), Chun Chieh Fan (Department of Cognitive Science, University of California San Diego, San Diego, USA), Iryna O. Fedko (Department of Biological Psychology, Vrije Universiteit Amsterdam, Amsterdam, The Netherlands), Sonya F. Foley (Cardiff University Brain Research Imaging Centre, Cardiff University, Cardiff, UK), Judith M. Ford (San Francisco Veterans Administration Medical Center, San Francisco, USA), Masaki Fukunaga (Division of Cerebral Integration, National Institute for Physiological Sciences, Okazaki, Japan), Melanie E. Garrett (Duke Molecular Physiology Institute, Duke University Medical Center, Durham, USA), Tian Ge (Psychiatric and Neurodevelopmental Genetics Unit, Center for Genomic Medicine, Massachusetts General Hospital, Boston, USA), Sudheer Giddaluru (NORMENT - K.G. Jebsen Centre for Psychosis Research, Department of Clinical Science, NORMENT University of Bergen, Bergeb, Norway), Aaron L. Goldman (Lieber Institute for Brain Development, Baltimore, USA), Nynke A. Groenewold (Department of Psychiatry and Mental Health, University of Cape Town, Cape Town, South Africa), Dominik Grotegerd (Department of Psychiatry, University of Münster, Münster, Germany), Tiril P. Gurholt (NORMENT - K.G. Jebsen Centre for Psychosis Research, Division of Mental Health and Addiction, NORMENT Oslo University Hospital, Oslo, Norway), Boris A. Gutman (Imaging Genetics Center, Mark and Mary Stevens Neuroimaging and Informatics Institute, Keck School of Medicine of USC, University of Southern California, Los Angeles, USA), Narelle K. Hansell (Queensland Brain Institute, University of Queensland, St Lucia, Australia), Mathew A. Harris (Centre for Clinical Brain Sciences and Edinburgh Imaging, University of Edinburgh, Edinburgh, UK), Marc B. Harrison (Imaging Genetics Center, Mark and Mary Stevens Neuroimaging and Informatics Institute, Keck School of Medicine of USC, University of Southern California, Los Angeles, USA), Courtney C. Haswell (Duke UNC Brain Imaging and Analysis Center, Duke University Medical Center, Durham, USA), Michael Hauser (Duke Molecular Physiology Institute, Duke University Medical Center, Durham, USA), Stefan Herms (Department of Biomedicine, University of Basel, Basel, Switzerland), Dirk J. Heslenfeld (Department of Cognitive and Clinical Neuropsychology, Vrije Universiteit Amsterdam, Amsterdam, The Netherlands), New Fei Ho (Research Division, Institute of Mental Health, Singapore, Singapore), David Hoehn (Max Planck Institute of Psychiatry, Munich, Germany), Per Hoffmann (Department of Biomedicine, University of Basel, Basel, Switzerland), Laurena Holleran (Centre for Neuroimaging \& Cognitive Genomics, National University of Ireland Galway, Galway, Ireland), Martine Hoogman (Department of Human Genetics, Radboud university medical center, Nijmegen, The Netherlands), Jouke-Jan Hottenga (Department of Biological Psychology, Vrije Universiteit Amsterdam, Amsterdam, The Netherlands), Masashi Ikeda (Department of Psychiatry, Fujita Health University School of Medicine, Toyoake, Japan), Deborah Janowitz (Department of Psychiatry and Psychotherapy, University Medicine Greifswald, Greifswald, Germany), Iris E. Jansen (Complex Trait Genetics, Center for Neurogenomics and Cognitive Research, Vrije Universiteit Amsterdam, Amsterdam, The Netherlands), Tianye Jia (Institute of Science and Technology for Brain-Inspired Intelligence, Fudan University, Shanghai, China), Christiane Jockwitz (Institute of Neuroscience and Medicine (INM-1), Research Centre Jülich, Jülich, Germany), Ryota Kanai (Department of Neuroinformatics, Araya, Inc., Tokyo, Japan), Sherif Karama (Department of Psychiatry, McGill University, Montreal, Canada), Dalia Kasperaviciute (Department of Clinical and Experimental Epilepsy, UCL Institute of Neurology, London, UK), Tobias Kaufmann (NORMENT - K.G. Jebsen Centre for Psychosis 
bioRxiv preprint first posted online Sep. 9, 2018; doi: http://dx.doi.org/10.1101/409649. The copyright holder for this preprint (which was not peer-reviewed) is the author/funder, who has granted bioRxiv a license to display the preprint in perpetuity.

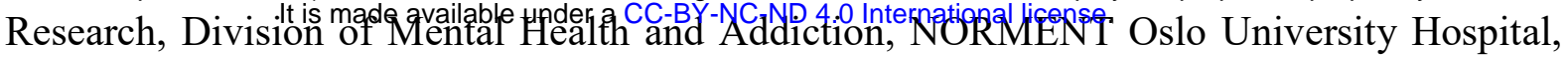
Oslo, Norway), Sinead Kelly (Public Psychiatry Division, Massachusetts Mental Health Center, Beth Israel Deaconess Medical Center, Harvard Medical School, Boston, USA), Masataka Kikuchi (Department of Genome Informatics, Graduate School of Medicine, Osaka University, Suita, Japan), Marieke Klein (Department of Human Genetics, Radboud university medical center, Nijmegen, The Netherlands), Michael Knapp (Department of Medical Biometry, Informatics and Epidemiology, University Hospital Bonn, Bonn, Germany), Annchen R. Knodt (Department of Psychology and Neuroscience, Duke University, Durham, USA), Bernd Krämer (Section for Experimental Psychopathology and Neuroimaging, Department of General Psychiatry, Heidelberg University Hospital, Heidelberg, Germany), Max Lam (Research Division, Institute of Mental Health, Singapore, Singapore), Thomas M. Lancaster (Cardiff University Brain Research Imaging Centre, Cardiff University, Cardiff, UK), Phil H. Lee (Psychiatric and Neurodevelopmental Genetics Unit, Center for Genomic Medicine, Massachusetts General Hospital, Boston, USA), Tristram A. Lett (Division of Mind and Brain Research, Department of Psychiatry and Psychotherapy, Campus Charité Mitte, Charité - Universitätsmedizin Berlin, Berlin, Germany), Lindsay B. Lewis (McGill Centre for Integrative Neuroscience, McGill University, Montreal, Canada), Iscia Lopes-Cendes (Department of Medical Genetics, School of Medical Sciences, University of Campinas UNICAMP, Campinas, Brazil), Michelle Luciano (Department of Psychology, University of Edinburgh, Edinburgh, UK), Fabio Macciardi (Department of Psychiatry and Human Behavior, School of Medicine, University of California, Irvine, Irvine, USA), Andre F. Marquand (Department of Cognitive Neuroscience, Radboud university medical center, Nijmegen, The Netherlands), Samuel R. Mathias (Department of Psychiatry, Yale University School of Medicine, New Haven, USA), Tracy R. Melzer (Department of Medicine, University of Otago, Christchurch, Christchurch, New Zealand), Yuri Milaneschi (Psychiatry, Amsterdam UMC Vrije Universiteit, Amsterdam, The Netherlands), Nazanin Mirza-Schreiber (Max Planck Institute of Psychiatry, Munich, Germany), Jose C.V. Moreira (BRAINN - Brazilian Institute of Neuroscience and Neurotechnology, Campinas, Brazil), Thomas W. Mühleisen (Institute of Neuroscience and Medicine (INM-1), Research Centre Jülich, Jülich, Germany), Bertram Müller-Myhsok (Max Planck Institute of Psychiatry, Munich, Germany), Pablo Najt (Centre for Neuroimaging \& Cognitive Genomics, National University of Ireland Galway, Galway, Ireland), Soichiro Nakahara (Department of Psychiatry and Human Behavior, School of Medicine University of California, University of California, Irvine, Irvine, USA), Kwangsik Nho (Department of Radiology and Imaging Sciences, Indiana University School of Medicine, Indianapolis, USA), Loes M. Olde Loohuis (Center for Neurobehavioral Genetics, University of California Los Angeles, Los Angeles, USA), Dimitri Papadopoulos Orfanos (NeuroSpin, CEA, Université Paris-Saclay, Gif sur Yvette, France), John F. Pearson (Biostatistics and Computational Biology Unit, University of Otago, Christchurch, Christchurch, New Zealand), Toni L. Pitcher (Department of Medicine, University of Otago, Christchurch, Christchurch, New Zealand), Benno Pütz (Max Planck Institute of Psychiatry, Munich, Germany), Anjanibhargavi Ragothaman (Imaging Genetics Center, Mark and Mary Stevens Neuroimaging and Informatics Institute, Keck School of Medicine of USC, University of Southern California, Los Angeles, USA), Faisal M. Rashid (Imaging Genetics Center, Mark and Mary Stevens Neuroimaging and Informatics Institute, Keck School of Medicine of USC, University of Southern California, Los Angeles, USA), Ronny Redlich (Department of Psychiatry, University of Münster, Münster, Germany), Céline S. Reinbold (Department of Biomedicine, University of Basel, Basel, Switzerland), Jonathan Repple (Department of Psychiatry, University of Münster, Münster, Germany), Geneviève Richard (NORMENT K.G. Jebsen Centre for Psychosis Research, Division of Mental Health and Addiction, NORMENT Oslo University Hospital, Oslo, Norway), Brandalyn C. Riedel (Imaging Genetics Center, Mark and Mary Stevens Neuroimaging and Informatics Institute, Keck School of Medicine of USC, University of Southern California, Los Angeles, USA), Shannon L. Risacher (Department of Radiology and Imaging Sciences, Indiana University School of Medicine, 

bioRxiv preprint first posted online Sep. 9, 2018; doi: http://dx.doi.org/10.1101/409649. The copyright holder for this preprint
(which was not peer-reviewed) is the author/funder, who has granted bioRxiv a license to display the preprint in perpetuity.

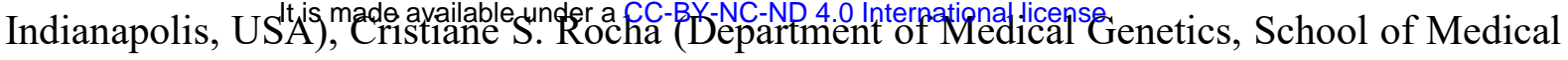
Sciences, University of Campinas - UNICAMP, Campinas, Brazil), Nina Roth Mota (Department of Human Genetics, Radboud university medical center, Nijmegen, The Netherlands), Lauren Salminen (Imaging Genetics Center, Mark and Mary Stevens Neuroimaging and Informatics Institute, Keck School of Medicine of USC, University of Southern California, Los Angeles, USA), Arvin Saremi (Imaging Genetics Center, Mark and Mary Stevens Neuroimaging and Informatics Institute, Keck School of Medicine of USC, University of Southern California, Los Angeles, USA), Andrew J. Saykin (Department of Radiology and Imaging Sciences, Indiana University School of Medicine, Indianapolis, USA), Fenja Schlag (Language and Genetics Department, Max Planck Institute for Psycholinguistics, Nijmegen, The Netherlands), Lianne Schmaal (Orygen, The National Centre of Excellence for Youth Mental Health, Melbourne, Australia), Peter R. Schofield ( Neuroscience Research Australia, Sydney, Australia), Rodrigo Secolin (Department of Medical Genetics, School of Medical Sciences, University of Campinas - UNICAMP, Campinas, Brazil), Chin Yang Shapland (Language and Genetics Department, Max Planck Institute for Psycholinguistics, Nijmegen, The Netherlands), Li Shen (Department of Biostatistics, Epidemiology and Informatics, University of Pennsylvania, Philadelphia, USA), Jean Shin (The Hospital for Sick Children, University of Toronto, Toronto, Canada), Elena Shumskaya (Department of Human Genetics, Radboud university medical center, Nijmegen, The Netherlands), Ida E. Sønderby (NORMENT - K.G. Jebsen Centre for Psychosis Research, Division of Mental Health and Addiction, NORMENT Oslo University Hospital, Oslo, Norway), Emma Sprooten (Donders Institute for Brain, Cognition and Behaviour, Radboud University, Nijmegen, The Netherlands), Lachlan T. Strike (Queensland Brain Institute, University of Queensland, St Lucia, Australia), Katherine E. Tansey (MRC Centre for Neuropsychiatric Genetics and Genomics, Cardiff University, Cardiff, UK), Alexander Teumer (Institute for Community Medicine, University Medicine Greifswald, Greifswald, Germany), Anbupalam Thalamuthu (Centre for Healthy Brain Ageing, University of New South Wales, Sydney, Australia), Sophia I. Thomopoulos (Imaging Genetics Center, Mark and Mary Stevens Neuroimaging and Informatics Institute, Keck School of Medicine of USC, University of Southern California, Los Angeles, USA), Diana Tordesillas-Gutiérrez (Neuroimaging Unit, Valdecilla Biomedical Research Institute IDIVAL, Santander, Spain), Jessica A. Turner (Department of Psychology, Georgia State University, Atlanta, USA), Anne Uhlmann (Department of Psychiatry and Mental Health, University of Cape Town, Cape Town, South Africa), Costanza Ludovica Vallerga (Institute for Molecular Bioscience, The University of Queensland, Brisbane, Australia), Dennis van der Meer (NORMENT - K.G. Jebsen Centre for Psychosis Research, Division of Mental Health and Addiction, NORMENT Oslo University Hospital, Oslo, Norway), Marjolein M.J. van Donkelaar (Department of Human Genetics, Radboud university medical center, Nijmegen, The Netherlands), Liza van Eijk (School of Psychology, University of Queensland, Brisbane, Australia), Theo G.M. van Erp (Department of Psychiatry and Human Behavior, School of Medicine University of California, University of California, Irvine, Irvine, USA), Neeltje E.M. van Haren (Department of Psychiatry, Brain Center Rudolf Magnus, University Medical Center Utrecht, Utrecht University, Utrecht, The Netherlands), Daan van Rooij (Department of Cognitive Neuroscience, Radboud university medical center, Nijmegen, The Netherlands), Marie-José van Tol (Cognitive Neuroscience Center, Department of Neuroscience, University Medical Center Groningen, Groningen, The Netherlands), Jan H. Veldink (Department of Neurology, Brain Center Rudolf Magnus, University Medical Center Utrecht, Utrecht University, Utrecht, The Netherlands), Ellen Verhoef (Language and Genetics Department, Max Planck Institute for Psycholinguistics, Nijmegen, The Netherlands), Esther Walton (Department of Psychology, Georgia State University, Atlanta, USA), Mingyuan Wang (Research Division, Institute of Mental Health, Singapore, Singapore), Yunpeng Wang (NORMENT - K.G. Jebsen Centre for Psychosis Research, Division of Mental Health and Addiction, NORMENT Oslo University Hospital, Oslo, Norway), Joanna M. Wardlaw (Centre for Clinical Brain Sciences and Edinburgh Imaging, University of Edinburgh, Edinburgh, UK), 
bioRxiv preprint first posted online Sep. 9, 2018; doi: http://dx.doi.org/10.1101/409649. The copyright holder for this preprint (which was not peer-reviewed) is the author/funder, who has granted bioRxiv a license to display the preprint in perpetuity.

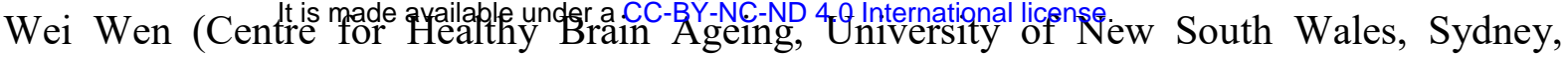
Australia), Lars T. Westlye (NORMENT - K.G. Jebsen Centre for Psychosis Research, Division of Mental Health and Addiction, NORMENT Oslo University Hospital, Oslo, Norway), Christopher D. Whelan (Imaging Genetics Center, Mark and Mary Stevens Neuroimaging and Informatics Institute, Keck School of Medicine of USC, University of Southern California, Los Angeles, USA), Stephanie H. Witt (Department of Genetic Epidemiology in Psychiatry, Central Institute of Mental Health, Medical Faculty Mannheim, Heidelberg University, Mannheim, Germany), Katharina Wittfeld (, German Center for Neurodegenerative Diseases Rostock/Greifswald, Greifswald, Germany), Christiane Wolf (Department of Psychiatry, Psychosomatics and Psychotherapy, University of Würzburg, Würzburg, Germany), Thomas Wolfers (Department of Human Genetics, Radboud university medical center, Nijmegen, The Netherlands), Clarissa L. Yasuda (Department of Neurology, FCM, University of Campinas - UNICAMP, Campinas, Brazil), Dario Zaremba (Department of Psychiatry, University of Münster, Münster, Germany), Zuo Zhang (Social, Genetic and Developmental Psychiatry Centre, Institute of Psychiatry, Psychology \& Neuroscience, King's College London, London, UK), Alyssa H. Zhu (Imaging Genetics Center, Mark and Mary Stevens Neuroimaging and Informatics Institute, Keck School of Medicine of USC, University of Southern California, Los Angeles, USA), Marcel P. Zwiers (Department of Cognitive Neuroscience, Radboud university medical center, Nijmegen, The Netherlands), Eric Artiges (INSERM Unit 1000 - Neuroimaging \& Psychiatry, Paris Saclay University, Gif sur Yvette, France), Amelia A. Assareh (Centre for Healthy Brain Ageing, University of New South Wales, Sydney, Australia), Rosa Ayesa-Arriola (Department of Psychiatry, University Hospital Marqués de Valdecilla, School of Medicine, University of Cantabria-IDIVAL, Santander, Spain), Aysenil Belger (Duke UNC Brain Imaging and Analysis Center, Duke University Medical Center, Durham, USA), Christine L. Brandt (NORMENT - K.G. Jebsen Centre for Psychosis Research, Division of Mental Health and Addiction, NORMENT Oslo University Hospital, Oslo, Norway), Gregory G. Brown (Department of Psychiatry, University of California San Diego, San Diego, USA), Sven Cichon (Department of Biomedicine, University of Basel, Basel, Switzerland), Joanne E. Curran (Department of Human Genetics and South Texas Diabetes and Obesity Institute, Rio Grande Valley School of Medicine, University of Texas, Brownsville, USA), Gareth E. Davies (Avera Institute for Human Genetics, Sioux Falls, USA), Franziska Degenhardt (Institute of Human Genetics, School of Medicine \& University Hospital Bonn, University of Bonn, Bonn, Germany), Bruno Dietsche (Department of Psychiatry and Psychotherapy, Philipps-University Marburg, Marburg, Germany), Srdjan Djurovic (Department of Medical Genetics, Oslo University Hospital, Oslo, Norway), Colin P. Doherty (Department of Neurology, St James's Hospital, Dublin, Ireland), Ryan Espiritu (Information Sciences Institute, University of Southern California, Los Angeles, USA), Daniel Garijo (Information Sciences Institute, University of Southern California, Los Angeles, USA), Yolanda Gil (Information Sciences Institute, University of Southern California, Los Angeles, USA), Penny A. Gowland (Sir Peter Mansfield Imaging Centre, University of Nottingham, Nottingham, UK), Robert C. Green (, Brigham and Women's Hospital, Boston, USA), Alexander N. Häusler (Center for Economics and Neuroscience, University of Bonn, Bonn, Germany), Walter Heindel (Department of Clinical Radiology, University of Münster, Münster, Germany), Beng-Choon Ho (Department of Psychiatry, University of Iowa College of Medicine, Iowa City, USA), Wolfgang U. Hoffmann (Institute for Community Medicine, University Medicine Greifswald, Greifswald, Germany), Florian Holsboer (HMNC Holding GmbH, Munich, Germany), Georg Homuth (Department of Functional Genomics, Interfaculty Institute for Genetics and Functional Genomics, University Medicine Greifswald, Greifswald, Germany), Norbert Hosten (Institute of Diagnostic Radiology and Neuroradiology, University Medicine, Ernst-Moritz-Arndt University, Greifswald, Germany), Clifford R. Jack Jr. (Dept of Radiology, Mayo Clinic, Rochester, USA), MiHyun Jang (Information Sciences Institute, University of Southern California, Los Angeles, USA), Andreas Jansen (Department of Psychiatry and Psychotherapy, Philipps-University 

bioRxiv preprint first posted online Sep. 9,2018 ; doi: http://dx.doi.org/10.1101/409649. The copyright holder for this preprint
(which was not peer-reviewed) is the author/funder, who has granted bioRxiv a license to display the preprint in perpetuity.

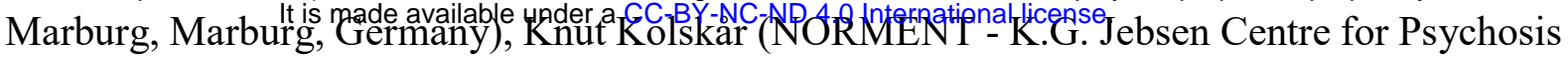
Research, Division of Mental Health and Addiction, NORMENT Oslo University Hospital, Oslo, Norway), Sanne Koops (Department of Psychiatry, Brain Center Rudolf Magnus, University Medical Center Utrecht, Utrecht University, Utrecht, The Netherlands), Axel Krug (Department of Psychiatry and Psychotherapy, Philipps-University Marburg, Marburg, Germany), Kelvin O. Lim (Department of Psychiatry, University of Minnesota, Minneapolis, USA), Jurjen J. Luykx (Department of Translational Neuroscience, Brain Center Rudolf Magnus, University Medical Center Utrecht, Utrecht University, Utrecht, The Netherlands), Daniel H. Mathalon (Department of Psychiatry and Weill Institute for Neurosciences, University of California San Francisco, San Francisco, USA), Karen A. Mather (Centre for Healthy Brain Ageing, University of New South Wales, Sydney, Australia), Venkata S. Mattay (Lieber Institute for Brain Development, Baltimore, USA), Sarah Matthews (MRC Integrative Epidemiology Unit, Department of Population Health Sciences, Bristol Medical School, Bristol, UK), Jaqueline Mayoral Van Son (Department of Psychiatry, University Hospital Marqués de Valdecilla, School of Medicine, University of Cantabria-IDIVAL, Santander, Spain), Sarah C. McEwen (Department of Psychiatry, University of California San Diego, La Jolla, USA), Ingrid Melle (NORMENT - K.G. Jebsen Centre for Psychosis Research, Division of Mental Health and Addiction, NORMENT Oslo University Hospital, Oslo, Norway), Derek W. Morris (Centre for Neuroimaging \& Cognitive Genomics, National University of Ireland Galway, Galway, Ireland), Bryon A. Mueller (Department of Psychiatry, University of Minnesota, Minneapolis, USA), Matthias Nauck (Institute of Clinical Chemistry and Laboratory Medicine, University Medicine Greifswald, Greifswald, Germany), Jan E. Nordvik (Sunnaas Rehabilitation Hospital HT, Nesodden, Norway), Markus M. Nöthen (Institute of Human Genetics, School of Medicine \& University Hospital Bonn, University of Bonn, Bonn, Germany), Daniel S. O'Leary (Department of Psychiatry, University of Iowa College of Medicine, Iowa City, USA), Nils Opel (Department of Psychiatry, University of Münster, Münster, Germany), Marie - Laure Paillère Martinot (INSERM Unit 1000 - Neuroimaging \& Psychiatry, Paris Saclay University, Gif sur Yvette, France), G. Bruce Pike (Radiology and Clinical Neurosciences, Hotchkiss Brain Institute, University of Calgary, Calgary, Canada), Adrian Preda (School of Medicine, University of California Irvine, Irvine, USA), Erin B. Quinlan (Social, Genetic and Developmental Psychiatry Centre, King's College London, London, UK), Varun Ratnakar (Information Sciences Institute, University of Southern California, Los Angeles, USA), Simone Reppermund (Centre for Healthy Brain Ageing, University of New South Wales, Sydney, Australia), Vidar M. Steen (NORMENT - K.G. Jebsen Centre for Psychosis Research, Department of Clinical Science, NORMENT University of Bergen, Bergen, Norway), Fábio R. Torres (Department of Medical Genetics, School of Medical Sciences, University of Campinas - UNICAMP, Campinas, Brazil), Dick J. Veltman (Psychiatry, Amsterdam UMC Vrije Universiteit, Amsterdam, The Netherlands), James T. Voyvodic (Duke UNC Brain Imaging and Analysis Center, Duke University Medical Center, Durham, USA), Robert Whelan (School of Psychology, Trinity College Dublin, Dublin, Ireland), Tonya White (Department of Child and Adolescent Psychiatry/Psychology, Erasmus Medical Center-Sophia Children's Hospital, Rotterdam, The Netherlands), Hidenaga Yamamori (Department of Psychiatry, Osaka University Graduate School of Medicine, Suita, Japan), Marina K.M. Alvim (Department of Neurology, FCM, University of Campinas UNICAMP, Campinas, Brazil), David Ames (Academic Unit for Psychiatry of Old Age, University of Melbourne, Melbourne, Australia), Tim J. Anderson (Department of Medicine, University of Otago, Christchurch, Christchurch, New Zealand), Ole A. Andreassen (NORMENT - K.G. Jebsen Centre for Psychosis Research, Division of Mental Health and Addiction, NORMENT Oslo University Hospital, Oslo, Norway), Alejandro Arias-Vasquez (Department of Psychiatry, Radboud university medical center, Nijmegen, The Netherlands), Mark E. Bastin (Centre for Clinical Brain Sciences and Edinburgh Imaging, University of Edinburgh, Edinburgh, UK), Bernhard T. Baune (Department of Psychiatry, The University of Melbourne, Melbourne, Australia.), John Blangero (Department of Human Genetics and South 
bioRxiv preprint first posted online Sep. 9, 2018; doi: http://dx.doi.org/10.1101/409649. The copyright holder for this preprint (which was not peer-reviewed) is the author/funder, who has granted bioRxiv a license to display the preprint in perpetuity.

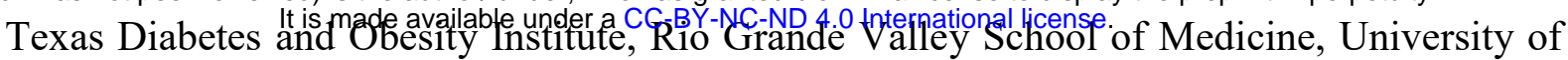
Texas, Brownsville, USA), Dorret I. Boomsma (Department of Biological Psychology, Vrije Universiteit Amsterdam, Amsterdam, The Netherlands), Henry Brodaty (Centre for Healthy Brain Ageing, University of New South Wales, Sydney, Australia), Han G. Brunner (Department of Human Genetics, Radboud university medical center, Nijmegen, The Netherlands), Randy L. Buckner (Department of Psychology and Center for Brain Science, Harvard University, Boston, USA), Jan K. Buitelaar (Department of Cognitive Neuroscience, Radboud university medical center, Nijmegen, The Netherlands), Juan R. Bustillo (Department of Psychiatry, University of New Mexico, Albuquerque, USA), Wiepke Cahn (Department of Psychiatry, University Medical Center Utrecht, Utrecht University, Utrecht, The Netherlands), Vince Calhoun (Department of Electrical and Computer Engineering, The University of New Mexico, Albuquerque, USA), Xavier Caseras (MRC Centre for Neuropsychiatric Genetics and Genomics, Cardiff University, Cardiff, UK), Svenja Caspers (Institute for Anatomy I Medical Faculty, Heinrich-Heine University, Düsseldorf, Germany), Gianpiero L. Cavalleri (Molecular and Cellular Therapeutics, The Royal College of Surgeons In Ireland, Dublin, Ireland), Fernando Cendes (Department of Neurology, FCM, University of Campinas - UNICAMP, Campinas, Brazil), Aiden Corvin (Department of Psychiatry, School of Medicine, Trinity College Dublin, Dublin, Ireland), Benedicto Crespo-Facorro (Department of Psychiatry, University Hospital Marqués de Valdecilla, School of Medicine, University of CantabriaIDIVAL, Santander, Spain), John C. Dalrymple-Alford (Department of Psychology, University of Canterbury, Christchurch, New Zealand), Udo Dannlowski (Department of Psychiatry, University of Münster, Münster, Germany), Eco J.C. de Geus (Department of Biological Psychology, Vrije Universiteit Amsterdam, Amsterdam, The Netherlands), Ian J. Deary (Centre for Cognitive Ageing and Cognitive Epidemiology, University of Edinburgh, Edinburgh, UK), Norman Delanty (FutureNeuro Research Centre, Royal College of Surgeons in Ireland, Dublin, Ireland), Chantal Depondt (Department of Neurology, Hôpital Erasme, Université Libre de Bruxelles, Brussels, Belgium), Sylvane Desrivières (Social, Genetic and Developmental Psychiatry Centre, King's College London, London, UK), Gary Donohoe (Centre for Neuroimaging \& Cognitive Genomics, National University of Ireland Galway, Galway, Ireland), Thomas Espeseth (Department of Psychology, University of Oslo, Oslo, Norway), Guillén Fernández (Department of Cognitive Neuroscience, Radboud university medical center, Nijmegen, The Netherlands), Simon E. Fisher (Language and Genetics Department, Max Planck Institute for Psycholinguistics, Nijmegen, The Netherlands), Herta Flor (Department of Cognitive and Clinical Neuroscience, Central Institute of Mental Health, Medical Faculty Mannheim, Heidelberg University, Mannheim, Germany), Andreas J. Forstner (Institute of Human Genetics, School of Medicine \& University Hospital Bonn, University of Bonn, Bonn, Germany), Clyde Francks (Language and Genetics Department, Max Planck Institute for Psycholinguistics, Nijmegen, The Netherlands), Barbara Franke (Department of Human Genetics, Radboud university medical center, Nijmegen, The Netherlands), David C. Glahn (Department of Psychiatry, Yale University School of Medicine, New Haven, USA), Randy L. Gollub (Department of Psychiatry, Massachusetts General Hospital, Boston, USA), Hans J. Grabe (German Center for Neurodegenerative Diseases Rostock/Greifswald, Greifswald, Germany), Oliver Gruber (Section for Experimental Psychopathology and Neuroimaging, Department of General Psychiatry, Heidelberg University Hospital, Heidelberg, Germany), Asta K. Håberg (Department of Neuroscience, Norwegian University of Science and Technology, Trondheim, Norway), Ahmad R. Hariri (Department of Psychology and Neuroscience, Duke University, Durham, USA), Catharina A. Hartman (Department of Psychiatry, University Medical Center Groningen, University of Groningen, Groningen, The Netherlands), Ryota Hashimoto (Molecular Research Center for Children's Mental Development, United Graduate School of Child Development, Osaka University, Suita, Japan), Andreas Heinz (Division of Mind and Brain Research, Department of Psychiatry and Psychotherapy, Campus Charité Mitte, Charité - Universitätsmedizin Berlin, Berlin, Germany), Manon H.J. Hillegers (Department of Child and Adolescent 
bioRxiv preprint first posted online Sep. 9, 2018; doi: http://dx.doi.org/10.1101/409649. The copyright holder for this preprint (which was not peer-reviewed) is the author/funder, who has granted bioRxiv a license to display the preprint in perpetuity.

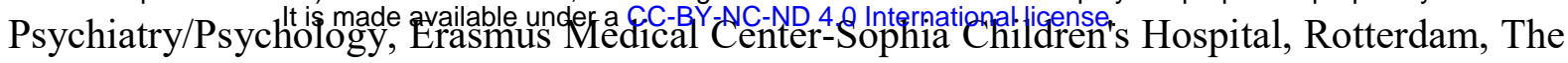
Netherlands), Pieter J. Hoekstra (Department of Psychiatry, University Medical Center Groningen, University of Groningen, Groningen, The Netherlands), Avram J. Holmes (Department of Psychology, Yale University, New Haven, USA), L. Elliot Hong (Department of Psychiatry, Maryland Psychiatry Research Center, University of Maryland School of Medicine, Baltimore, USA), William D. Hopkins (Neuroscience Institute, Georgia State University, Atlanta, USA), Hilleke E. Hulshoff Pol (Department of Psychiatry, Brain Center Rudolf Magnus, University Medical Center Utrecht, Utrecht University, Utrecht, The Netherlands), Terry L. Jernigan (Center for Human Development, University of California San Diego, La Jolla, USA), Erik G. Jönsson (Centre for Psychiatric Research, Department of Clinical Neuroscience, Karolinska Institutet, Stockholm, Sweden), René S. Kahn (Department of Psychiatry, Icahn School of Medicine at Mount Sinai, New York, USA), Martin A. Kennedy (Department of Pathology and Biomedical Science, University of Otago, Christchurch, Christchurch, New Zealand), Tilo T.J. Kircher (Department of Psychiatry and Psychotherapy, Philipps-University Marburg, Marburg, Germany), Peter Kochunov (Department of Psychiatry, Maryland Psychiatry Research Center, University of Maryland School of Medicine, Baltimore, USA), John B.J . Kwok (Neurogenetics and Epigenetics, Brain and Mind Centre, The University of Sydney, Sydney, Australia), Stephanie Le Hellard (NORMENT K.G. Jebsen Centre for Psychosis Research, Department of Clinical Science, NORMENT University of Bergen, Bergen, Norway), Nicholas G. Martin (Genetic Epidemiology, QIMR Berghofer Medical Research Institute, Brisbane, Australia), Jean - Luc Martinot (INSERM Unit 1000 - Neuroimaging \& Psychiatry, Paris Saclay University, Gif sur Yvette, France), Colm McDonald (Centre for Neuroimaging \& Cognitive Genomics, National University of Ireland Galway, Galway, Ireland), Katie L. McMahon (Herston Imaging Research Facility, School of Clinical Sciences, Queensland University of Technology, Brisbane, Australia), Andreas Meyer-Lindenberg (Department of Psychiatry and Psychotherapy, Central Institute of Mental Health, Medical Faculty Mannheim, Heidelberg University, Mannheim, Germany), Rajendra A. Morey (Duke UNC Brain Imaging and Analysis Center, Duke University Medical Center, Durham, USA), Lars Nyberg (Department of Integrative Medical Biology, Umeå University, Umeå, Sweden), Jaap Oosterlaan (Emma Children's Hospital, Academic Medical Center, Amsterdam, The Netherlands), Roel A. Ophoff (Center for Neurobehavioral Genetics, University of California Los Angeles, Los Angeles, USA), Tomáš Paus (Bloorview Research Institute, University of Toronto, Toronto, Canada), Zdenka Pausova (The Hospital for Sick Children, University of Toronto, Toronto, Canada), Brenda W.J.H. Penninx ( Psychiatry, Amsterdam UMC Vrije Universiteit, Amsterdam, The Netherlands), Tinca J.C. Polderman (Complex Trait Genetics, Center for Neurogenomics and Cognitive Research, Vrije Universiteit Amsterdam, Amsterdam, The Netherlands), Danielle Posthuma (Complex Trait Genetics, Center for Neurogenomics and Cognitive Research, Vrije Universiteit Amsterdam, Amsterdam, The Netherlands), Marcella Rietschel (Department of Genetic Epidemiology in Psychiatry, Central Institute of Mental Health, Medical Faculty Mannheim, Heidelberg University, Mannheim, Germany), Joshua L. Roffman (Department of Psychiatry, Massachusetts General Hospital, Boston, USA), Laura M. Rowland (Department of Psychiatry, Maryland Psychiatry Research Center, University of Maryland School of Medicine, Baltimore, USA), Perminder S. Sachdev (Centre for Healthy Brain Ageing, University of New South Wales, Sydney, Australia), Philipp G. Sämann (Max Planck Institute of Psychiatry, Munich, Germany), Gunter Schumann (Social, Genetic and Developmental Psychiatry Centre, King's College London, London, UK), Kang Sim (General Psychiatry, Institute of Mental Health, Singapore, Singapore), Sanjay M. Sisodiya (Department of Clinical and Experimental Epilepsy, UCL Institute of Neurology, London, UK), Jordan W. Smoller (Psychiatric and Neurodevelopmental Genetics Unit, Center for Genomic Medicine, Massachusetts General Hospital, Boston, USA), Iris E. Sommer (Department of Medical and Biological Psychology, University of Bergen, Bergen, Norway), Beate St Pourcain (MRC Integrative Epidemiology Unit, Department of Population Health Sciences, Bristol Medical School, Bristol, UK), Dan J. 
bioRxiv preprint first posted online Sep. 9, 2018; doi: http://dx.doi.org/10.1101/409649. The copyright holder for this preprint (which was not peer-reviewed) is the author/funder, who has granted bioRxiv a license to display the preprint in perpetuity.

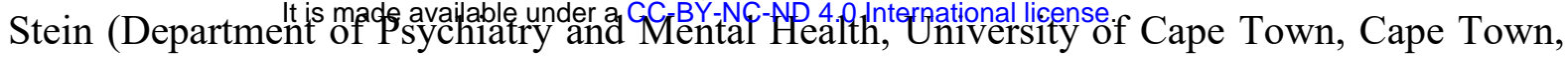
South Africa), Arthur W. Toga (Laboratory of Neuro Imaging, Mark and Mary Stevens Neuroimaging and Informatics Institute, Keck School of Medicine, University of Southern California, Los Angeles, USA), Julian N. Trollor (Department of Developmental Disability Neuropsychiatry, University of New South Wales, Sydney, Australia), Nic J.A. Van der Wee (Department of Psychiatry, Leiden University Medical Center, Leiden, The Netherlands), Dennis van 't Ent (Department of Biological Psychology, Vrije Universiteit Amsterdam, Amsterdam, The Netherlands), Henry Völzke (Institute for Community Medicine, University Medicine Greifswald, Greifswald, Germany), Henrik Walter (Division of Mind and Brain Research, Department of Psychiatry and Psychotherapy, Campus Charité Mitte, Charité Universitätsmedizin Berlin, Berlin, Germany), Bernd Weber (Institute of Experimental Epileptology and Cognition Research, University Hospital Bonn, Bonn, Germany), Daniel R. Weinberger (Lieber Institute for Brain Development, Baltimore, USA), Margaret J. Wright (Queensland Brain Institute, University of Queensland, St Lucia, Australia), Juan Zhou (Center for Cognitive Neuroscience, Neuroscience and behavioral disorders program, Duke-National University of Singapore Medical School, Singapore, Singapore), Jason L. Stein (Department of Genetics \& UNC Neuroscience Center, University of North Carolina at Chapel Hill, Chapel Hill, USA), Paul M. Thompson (Imaging Genetics Center, Mark and Mary Stevens Neuroimaging and Informatics Institute, Keck School of Medicine of USC, University of Southern California, Los Angeles, USA), and Sarah E. Medland (Psychiatric Genetics, QIMR Berghofer Medical Research Institute, Brisbane, Australia). 
bioRxiv preprint first posted online Sep. 9, 2018; doi: http://dx.doi.org/10.1101/409649. The copyright holder for this preprint (which was not peer-reviewed) is the author/funder, who has granted bioRxiv a license to display the preprint in perpetuity.

Author Contributions

Drafting of the Manuscript

Edith Hofer, Gennady V. Roshchupkin, Reinhold Schmidt, Sudha Seshadri

Genotype Data Acquisition

Helena Schmidt, Najaf Amin, Peter R Schofield, Margaret J Wright, Carol E. Franz, Margaret J Wright

Phenotype Data Acquisition

Reinhold Schmidt, Sophie Maingault., Bernard Mazoyer, Jiyang Jiang, Julian Trollor, G.

Bruce Pike, Carol E. Franz

Genetic Data Analysis and Bioinformatics Analysis

Edith Hofer, Yasaman Saba, Rui Xia, Josh C. Bis, Shahzad Ahmad, Shuo Li, Sven J van der Lee, Qiong Yang, Claudia Satizabal, Honghuang Lin, Jayandra J Himali, Habil Zare, Michelle Luciano, Markus Scholz, Nicola J. Armstrong, Gennady V. Roshchupkin, Hieab H. H. Adams, Maria J Knol, Meike W Vernooij, Alexander Teumer, Katharina Wittfeld, Manon Bernard, Aniket Mishra, Nathan A. Gillespie, Mark Logue, Peter R Schofield

Imaging Data Analysis

Gennady V. Roshchupkin, Hieab H. H. Adams, Lukas Pirpamer, Stephan Seiler, Pauline Maillard, Charles DeCarli, Sherif Karama, Lindsay Lewis, Mark Bastin, Wei Wen, Frauke Beyer, A. Veronica Witte, Mat Harris, Jiyang Jiang

Cohort PIs

Perminder S. Sachdev, William S. Kremen, Joanna A. Wardlaw, Arno Villringer, Cornelia M. van Duijn, Hans Jörgen Grabe, William T. Longstreth Jr, Myriam Fornage, Tomas Paus, Stephanie Debette, M. Arfan Ikram, Helena Schmidt, Reinhold Schmidt, Sudha Seshadri, Jerome I Rotter, Bruce M Psaty, Ian J Deary, Markus Loeffler, Albert Hofman, André G Uitterlinden, Wiro J Niessen, Zdenka Pausova, Matthew S. Panizzon, Thomas H Mosley, Julian Trollor, Carol E. Franz

ENIGMA Study Design

Katrina L. Grasby, Neda Jahanshad, Jodie N. Painter, Lucía Colodro-Conde, Janita Bralten, Derrek P. Hibar, Penelope A. Lind, Fabrizio Pizzagalli,Jason L. Stein, Paul M. Thompson, Sarah E. Medland 
bioRxiv preprint first posted online Sep. 9, 2018; doi: http://dx.doi.org/10.1101/409649. The copyright holder for this preprint (which was not peer-reviewed) is the author/funder, who has granted bioRxiv a license to display the preprint in perpetuity.

Conflict of Interest ${ }^{\text {It is made available under a CC-BY-NC-ND } 4.0 \text { International license. }}$

Dr. Dale is a Founder of and holds equity in CorTechs Labs, Inc, and serves on its Scientific Advisory Board. He is a member of the Scientific Advisory Board of Human Longevity, Inc. and receives funding through research agreements with General Electric Healthcare and Medtronic, Inc. The terms of these arrangements have been reviewed and approved by UCSD in accordance with its conflict of interest policies. W. Niessen is co-founder and shareholder of Quantib BV. None of the other authors declare any competing financial interests. 
bioRxiv preprint first posted online Sep. 9, 2018; doi: http://dx.doi.org/10.1101/409649. The copyright holder for this preprint (which was not peer-reviewed) is the author/funder, who has granted bioRxiv a license to display the preprint in perpetuity.

It is made available under a CC-BY-NC-ND 4.0 International license.

Table 1. Genome-wide significant associations (pDiscovery $<1.09 \times 10-9)$ of regional cortical thickness (lowest $p$-value of each cortical region at each genomic locus)

\begin{tabular}{|c|c|c|c|c|c|c|c|c|c|c|}
\hline Lobe & Region & Locus & Position & Lead SNP & Nearest Gene & Annotation & $\mathbf{N}$ & PDiscovery & Preplication & Ppooled \\
\hline \multirow{5}{*}{ temporal } & \multirow{2}{*}{ superior temporal } & $16 q 24.2$ & 87225139 & rs4843227 & LOC101928708 & intergenic & 21887 & $2.79 \mathrm{E}-12$ & 2.45E-05 & $2.31 \mathrm{E}-15$ \\
\hline & & $17 q 21.31$ & 44861003 & rs199504 & WNT3 & intronic & 21887 & $1.30 \mathrm{E}-10$ & 1.17E-04 & $5.85 E-13$ \\
\hline & middle temporal & $14 q 23.1$ & 59072144 & rs10782438 & KIAA0586 & intergenic & 21559 & $2.17 E-13$ & $2.76 E-08$ & 8.99E-21 \\
\hline & inferior temporal & $2 q 35$ & 217332057 & rs284532 & SMARCAL1 & intronic & 21885 & $1.03 E-09$ & 2.64E-01 & $3.04 \mathrm{E}-07$ \\
\hline & banksts & $14 q 23.1$ & 59074878 & rs160458 & KIAA05861 & intergenic & 18342 & $9.39 \mathrm{E}-10$ & 2.42E-09 & $6.45 \mathrm{E}-18$ \\
\hline \multirow{3}{*}{ parietal } & \multirow{2}{*}{ superior parietal } & $16 q 24.2$ & 87225101 & rs9937293 & LOC101928708 & intergenic & 21886 & $2.68 \mathrm{E}-14$ & $1.64 \mathrm{E}-13$ & $2.27 E-27$ \\
\hline & & $1 q 41$ & 215141570 & rs10494988 & KCNK2 & intergenic & 21886 & $2.60 \mathrm{E}-12$ & $3.66 \mathrm{E}-08$ & 2.63E-19 \\
\hline & postcentral & $15 q 14$ & 39633904 & rs2033939 & C15orf54 & intergenic & 21885 & $1.17 \mathrm{E}-73$ & $5.18 \mathrm{E}-68$ & $7.73 E-136$ \\
\hline \multirow{4}{*}{ occipital } & lateral occipital & $5 q 14.1$ & 79933093 & rs245100 & DHFR & intronic & 21886 & $2.68 \mathrm{E}-11$ & 3.77E-06 & $1.16 \mathrm{E}-15$ \\
\hline & cuneus & $14 q 23.1$ & 59624317 & rs4901904 & DAAM1 & intergenic & 21885 & $4.02 \mathrm{E}-14$ & $3.17 \mathrm{E}-10$ & $2.88 \mathrm{E}-23$ \\
\hline & \multirow{2}{*}{ insula } & $16 q 12.1$ & 51449978 & rs7197215 & SALL1 & intergenic & 21560 & $1.45 \mathrm{E}-13$ & $2.00 \mathrm{E}-02$ & $6.42 \mathrm{E}-12$ \\
\hline & & $9 q 31.3$ & 113679617 & rs72748157 & LPAR1 & intronic & 21560 & $1.46 \mathrm{E}-10$ & $1.38 \mathrm{E}-04$ & $5.16 \mathrm{E}-13$ \\
\hline
\end{tabular}

$\mathrm{N}$ : number of individuals in meta-analysis; piscovery: p-value of discovery GWAS meta-analysis in

CHARGE; p peplication: p-value of replication meta-analysis in ENIGMA; p pooled: p-value of pooled

discovery and replication meta-analysis; in bold: pReplication $<3.1 \times 10^{-4}(=0.05 / \mathrm{Nl}, \mathrm{Nl}=160$, total number of lead SNPs); banksts: banks of the superior temporal sulcus. 
bioRxiv preprint first posted online Sep. 9, 2018; doi: http://dx.doi.org/10.1101/409649. The copyright holder for this preprint (which was not peer-reviewed) is the author/funder, who has granted bioRxiv a license to display the preprint in perpetuity.

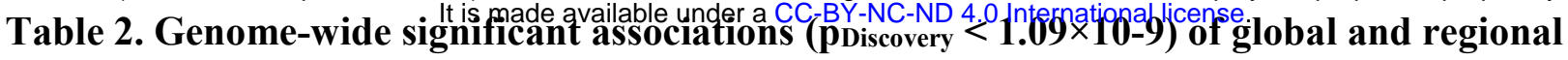
cortical surface area (lowest p-value of each cortical region at each genomic locus)

\begin{tabular}{|c|c|c|c|c|c|c|c|c|c|c|}
\hline Lobe & Region & Locus & Position & Lead SNP & Nearest Gene & Annotation & $\mathbf{N}$ & PDiscovery & PReplication & Ppooled \\
\hline & & $17 q 21.31$ & 44787313 & rs538628 & NSF & intronic & 18617 & $1.78 \mathrm{E}-23$ & $4.45 \mathrm{E}-22$ & $1.00 \mathrm{E}-43$ \\
\hline & & $6 q 22.32$ & 126792095 & rs11759026 & MIR588 & intergenic & 18617 & $5.21 \mathrm{E}-22$ & $1.45 \mathrm{E}-14$ & $3.50 \mathrm{E}-34$ \\
\hline & 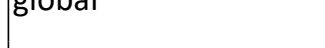 & $6 q 22.33$ & 127204623 & rs9375477 & RSPO3 & intergenic & 18617 & $4.86 \mathrm{E}-13$ & $1.60 \mathrm{E}-08$ & $1.23 \mathrm{E}-19$ \\
\hline & & $6 q 21$ & 109000316 & rs9398173 & FOXO3 & intronic & 18617 & $6.84 \mathrm{E}-10$ & $2.96 \mathrm{E}-03$ & $2.05 \mathrm{E}-10$ \\
\hline \multirow{7}{*}{ frontal } & superior frontal & $5 q 14.3$ & 92187932 & rs17669337 & NR2F1-AS1 & intergenic & 18272 & $1.40 \mathrm{E}-11$ & 2.05E-06 & 8.07E-16 \\
\hline & caudal middle frontal & $6 q 22.32$ & 126876580 & rs9388500 & RSPO3 & intergenic & 17891 & $2.35 \mathrm{E}-11$ & $\mathrm{NA}$ & NA \\
\hline & pars opercularis & $5 q 23.3$ & 128734008 & rs12187568 & ADAMTS19 & intergenic & 16632 & $1.19 \mathrm{E}-16$ & NA & NA \\
\hline & \multirow{2}{*}{ pars triangularis } & $3 q 24$ & 147106319 & rs2279829 & ZIC4 & UTR3 & 18265 & $6.32 \mathrm{E}-20$ & $1.94 \mathrm{E}-27$ & $1.20 \mathrm{E}-45$ \\
\hline & & $7 q 21.3$ & 96175094 & rs10458281 & LOC100506136 & intergenic & 18265 & $1.15 \mathrm{E}-17$ & 2.42E-11 & 1.20E-26 \\
\hline & \multirow[t]{2}{*}{ precentral } & $15 q 14$ & 39634222 & rs1080066 & C15orf54 & intergenic & 18267 & $\begin{array}{r}8.45 \mathrm{E}- \\
109\end{array}$ & 2.53E-95 & $\begin{array}{r}1.00 \mathrm{E}- \\
200\end{array}$ \\
\hline & & $6 q 15$ & 92002569 & rs9345124 & MAP3K7 & intergenic & 18267 & $5.50 \mathrm{E}-11$ & $2.73 E-14$ & 9.91E-24 \\
\hline \multirow{7}{*}{ temporal } & \multirow{3}{*}{ superior temporal } & $2 p 16.3$ & 48274592 & rs386645843 & FBX011 & intergenic & 18269 & $9.51 \mathrm{E}-12$ & 8.42E-07 & $1.71 \mathrm{E}-16$ \\
\hline & & $4 q 26$ & 119249835 & rs55699931 & PRSS12 & intronic & 18269 & $2.08 \mathrm{E}-11$ & $2.72 \mathrm{E}-02$ & $6.96 \mathrm{E}-10$ \\
\hline & & $2 q 23.2$ & 150022681 & rs13008194 & LYPD6B & intronic & 18269 & $5.94 \mathrm{E}-11$ & 2.54E-07 & $1.92 \mathrm{E}-16$ \\
\hline & middle temporal & $6 q 22.32$ & 126964510 & rs4273712 & RSPO3 & intergenic & 18269 & $6.93 \mathrm{E}-10$ & 1.07E-04 & $1.99 \mathrm{E}-12$ \\
\hline & banksts & $14 q 23.1$ & 59072226 & rs186347 & KIAA0586 & intergenic & 18265 & $4.11 \mathrm{E}-10$ & 1.83E-09 & $4.93 \mathrm{E}-18$ \\
\hline & fusiform & $17 q 21.31$ & 44822662 & rs199535 & NSF & intronic & 18269 & $1.01 \mathrm{E}-13$ & 1.14E-06 & $8.13 \mathrm{E}-18$ \\
\hline & transverse temporal & $2 q 23.2$ & 150012936 & rs2046268 & LYPD6B & intronic & 18264 & $9.09 \mathrm{E}-10$ & 3.21E-10 & $1.78 \mathrm{E}-18$ \\
\hline \multirow{14}{*}{ parietal } & \multirow{2}{*}{ superior parietal } & $15 q 14$ & 39632013 & rs71471500 & C15orf54 & intergenic & 18270 & $3.85 E-24$ & 5.55E-19 & $5.88 \mathrm{E}-41$ \\
\hline & & $19 p 13.2$ & 13109763 & rs68175985 & NFIX & intronic & 17324 & $8.84 \mathrm{E}-11$ & $2.68 \mathrm{E}-17$ & $2.90 \mathrm{E}-26$ \\
\hline & \multirow{3}{*}{ inferior parietal } & $20 q 13.2$ & 52448936 & rs6097618 & SUMO1P1 & intergenic & 18267 & $1.78 \mathrm{E}-16$ & NA & NA \\
\hline & & $12 q 14.3$ & 65797096 & rs2336713 & MSRB3 & intronic & 18267 & $1.24 \mathrm{E}-12$ & $2.99 \mathrm{E}-12$ & $2.85 \mathrm{E}-23$ \\
\hline & & $2 p 25.2$ & 4563477 & rs669952 & LINC01249 & intergenic & 18267 & 4.47E-10 & 1.37E-08 & 4.73E-17 \\
\hline & \multirow{3}{*}{ supramarginal } & $15 q 14$ & 39633904 & rs2033939 & C15orf54 & intergenic & 18272 & $9.07 \mathrm{E}-27$ & $1.61 \mathrm{E}-28$ & $1.59 E-53$ \\
\hline & & $14 q 23.1$ & 59627631 & rs2164950 & $D A A M 1$ & intergenic & 18272 & $1.25 \mathrm{E}-13$ & 3.79E-14 & $3.46 \mathrm{E}-26$ \\
\hline & & $3 q 24$ & 147106319 & rs2279829 & ZIC4 & UTR3 & 18272 & $7.38 \mathrm{E}-12$ & $4.24 \mathrm{E}-16$ & 2.29E-26 \\
\hline & \multirow{3}{*}{ postcentral } & $15 q 14$ & 39634222 & rs1080066 & C15orf54 & intergenic & 18265 & $5.65 E-47$ & $2.44 \mathrm{E}-36$ & $1.87 \mathrm{E}-80$ \\
\hline & & $3 q 24$ & 147106319 & rs2279829 & ZIC4 & UTR3 & 18265 & $1.90 \mathrm{E}-21$ & $1.69 \mathrm{E}-26$ & $2.92 \mathrm{E}-46$ \\
\hline & & $9 q 21.13$ & 76144318 & rs67286026 & ANXA1 & intergenic & 18265 & $3.58 \mathrm{E}-12$ & 8.04E-06 & 7.82E-16 \\
\hline & \multirow{3}{*}{ precuneus } & $14 q 23.1$ & 59628609 & rs74826997 & $D A A M 1$ & intergenic & 18270 & $2.40 \mathrm{E}-24$ & $4.41 \mathrm{E}-18$ & $4.59 \mathrm{E}-40$ \\
\hline & & $6 q 23.3$ & 138866268 & rs9376354 & NHSL1 & intronic & 18270 & $7.80 \mathrm{E}-13$ & 4.12E-08 & $7.28 \mathrm{E}-19$ \\
\hline & & $3 q 26$ & 190666643 & rs1159211 & SNAR-I & intergenic & 18270 & $4.49 \mathrm{E}-10$ & 2.04E-05 & 1.59E-13 \\
\hline \multirow{12}{*}{ occipital } & lateral occipital & $14 q 23.1$ & 59627631 & rs2164950 & $D A A M 1$ & intergenic & 18269 & $3.04 \mathrm{E}-26$ & 2.92E-15 & $2.25 \mathrm{E}-38$ \\
\hline & lingual & $14 q 23.1$ & 59628679 & rs76341705 & DAAM1 & intergenic & 18270 & $1.57 \mathrm{E}-20$ & 8.67E-13 & $9.96 \mathrm{E}-31$ \\
\hline & \multirow{2}{*}{ cuneus } & $14 q 23.1$ & 59625997 & rs73313052 & $D A A M 1$ & intergenic & 18267 & $1.90 \mathrm{E}-32$ & 3.19E-15 & $2.96 \mathrm{E}-43$ \\
\hline & & $13 q 31.1$ & 80191873 & rs9545155 & LINC01038 & intergenic & 18267 & $5.15 \mathrm{E}-10$ & $2.98 \mathrm{E}-05$ & $3.91 \mathrm{E}-13$ \\
\hline & \multirow{6}{*}{ pericalcarine } & $14 q 23.1$ & 59628679 & rs76341705 & $D A A M 1$ & intergenic & 18267 & 4.67E-24 & $2.56 \mathrm{E}-19$ & $3.35 \mathrm{E}-41$ \\
\hline & & $5 q 12.1$ & 60117723 & rs6893642 & ELOVL7 & intronic & 18267 & $1.40 \mathrm{E}-13$ & $1.68 \mathrm{E}-08$ & 6.29E-20 \\
\hline & & $3 q 13.11$ & 104724787 & rs971550 & $A L C A M$ & intergenic & 18267 & $2.18 \mathrm{E}-10$ & 1.31E-06 & $4.49 \mathrm{E}-15$ \\
\hline & & $6 q 22.33$ & 127185801 & rs9375476 & RSPO3 & intergenic & 18267 & $2.20 \mathrm{E}-10$ & 2.24E-08 & 4.32E-17 \\
\hline & & $1 p 13.2$ & 113239478 & rs2999158 & MoV10 & intronic & 18267 & $6.46 \mathrm{E}-10$ & $8.39 \mathrm{E}-10$ & $3.49 \mathrm{E}-18$ \\
\hline & & $13 q 31.1$ & 80191873 & rs9545155 & LINC01068 & intergenic & 18267 & $7.51 \mathrm{E}-10$ & 7.53E-09 & 4.05E-17 \\
\hline & posterior cingulate & $5 q 12.3$ & 66104105 & rs17214309 & MAST4 & intronic & 18268 & $7.84 \mathrm{E}-11$ & 1.52E-05 & 4.04E-14 \\
\hline & insula & $10 q 25.3$ & 118704077 & rs1905544 & SHTN1 & intronic & 17599 & $4.06 \mathrm{E}-12$ & 3.65E-03 & $1.28 \mathrm{E}-11$ \\
\hline
\end{tabular}

$\mathrm{N}$ : number of individuals in meta-analysis; pDiscovery: p-value of discovery GWAS meta-analysis in

CHARGE, pReplication: p-value of replication meta-analysis in ENIGMA; -p pooled: p-value of pooled

discovery and replication meta-analysis; in bold: $p_{\text {Replication }}<3.1 \times 10^{-4}(=0.05 / \mathrm{Nl}, \mathrm{Nl}=160$, total number of

lead SNPs); banksts: banks of the superior temporal sulcus. 
bioRxiv preprint first posted online Sep. 9, 2018; doi: http://dx.doi.org/10.1101/409649. The copyright holder for this preprint (which was not peer-reviewed) is the author/funder, who has granted bioRxiv a license to display the preprint in perpetuity.

Table 3. Genome-wide signnificant associations (pDiscovery $<1.09 \times 10-9)$ of global and regional cortical volume (lowest $p$-value of each cortical region at each genomic locus)

\begin{tabular}{|c|c|c|c|c|c|c|c|c|}
\hline Lobe & Region & Locus & Position & Lead SNP & Nearest gene & Annotation & $\mathbf{N}$ & PDiscovery \\
\hline & & $6 q 22.32$ & 126792095 & rs11759026 & MIR588 & intergenic & 22410 & $6.31 \mathrm{E}-19$ \\
\hline & & $17 q 21.31$ & 44790203 & rs169201 & $N S F$ & intronic & 22784 & $2.11 \mathrm{E}-13$ \\
\hline & olohal & $17 q 21.32$ & 43549608 & rs149366495 & PLEKHM1 & intronic & 22099 & $8.18 \mathrm{E}-13$ \\
\hline & giondl & $12 q 14.3$ & 66358347 & rs1042725 & HMGA2 & 3‘UTR & 22784 & 7.04E-11 \\
\hline & & $12 q 23.2$ & 102921296 & rs11111293 & IGF1 & intergenic & 22784 & $5.45 \mathrm{E}-10$ \\
\hline & & $6 q 22$ & 109002042 & rs4945816 & FOXO3 & 3`UTR & 22784 & $8.93 \mathrm{E}-10$ \\
\hline \multirow{14}{*}{ frontal } & superior frontal & $5 q 14.3$ & 92186429 & rs888814 & NR2F1-AS1 & intergenic & 22692 & $3.29 \mathrm{E}-13$ \\
\hline & rostral middle frontal & $15 q 14$ & 39636227 & rs17694988 & C15orf54 & intergenic & 22793 & $3.15 \mathrm{E}-11$ \\
\hline & \multirow{2}{*}{ caudal middle frontal } & $2 q 12.1$ & 105460333 & rs745249 & LINC01158 & ncRNA_intronic & 22726 & $2.35 \mathrm{E}-11$ \\
\hline & & $6 q 22.32$ & 127068983 & rs853974 & RSPO3 & intergenic & 22351 & $4.82 \mathrm{E}-11$ \\
\hline & \multirow{2}{*}{ pars opercularis } & $5 q 23.3$ & 128734008 & rs12187568 & ADAMTS19 & intergenic & 20753 & 4.27E-18 \\
\hline & & $15 q 14$ & 39639898 & rs4924345 & C15orf54 & intergenic & 22758 & $1.97 \mathrm{E}-14$ \\
\hline & \multirow{5}{*}{ pars triangularis } & $3 q 24$ & 147106319 & rs2279829 & ZIC4 & UTR3 & 22759 & $3.16 \mathrm{E}-23$ \\
\hline & & $7 q 21.3$ & 96196906 & rs67055449 & LOC100506136 & intergenic & 22759 & 4.03E-19 \\
\hline & & $15 q 14$ & 39633904 & rs2033939 & C15orf54 & intergenic & 22759 & $8.49 \mathrm{E}-14$ \\
\hline & & $7 q 21.3$ & 96129071 & rs62470042 & C7orf76 & intronic & 22759 & $7.38 \mathrm{E}-13$ \\
\hline & & $6 q 15$ & 91942761 & rs12660096 & MAPЗK7 & intergenic & 22759 & 4.74E-10 \\
\hline & lateral orbitofrontal & $14 q 22.2$ & 54769839 & rs6572946 & CDKN3 & intergenic & 22801 & $2.29 \mathrm{E}-10$ \\
\hline & nrecentral & $15 q 14$ & 39634222 & rs1080066 & C15orf54 & intergenic & 22699 & $5.84 \mathrm{E}-125$ \\
\hline & precemiral & $10 q 25.3$ & 118648841 & rs3781566 & SHTN1 & intronic & 22699 & 4.68E-11 \\
\hline \multirow{6}{*}{ temporal } & superior temporal & $3 q 26.32$ & 177296448 & rs13084960 & LINC00578 & ncRNA_intronic & 22681 & $1.12 \mathrm{E}-11$ \\
\hline & banksts & $14 q 23.1$ & 59072226 & rs186347 & KIAA0586 & intergenic & 22727 & $1.15 \mathrm{E}-15$ \\
\hline & \multirow{2}{*}{ fusiform } & $14 q 23.1$ & 59833172 & rs1547199 & $D A A M 1$ & intronic & 22605 & $4.58 \mathrm{E}-10$ \\
\hline & & $1 \mathrm{p} 33$ & 47980916 & rs6658111 & FOXD2 & intergenic & 22605 & 7.78E-10 \\
\hline & transverse temporal & $2 q 23.2$ & 150012936 & rs2046268 & $\angle Y P D 6 B$ & intronic & 22786 & $2.55 \mathrm{E}-12$ \\
\hline & parahippocampal & $2 q 33.1$ & 199809716 & rs966744 & SATB2 & intergenic & 22747 & $2.23 \mathrm{E}-10$ \\
\hline \multirow{18}{*}{ parietal } & \multirow{4}{*}{ superior parietal } & $15 q 14$ & 39633904 & rs2033939 & C15orf54 & intergenic & 22723 & $4.28 \mathrm{E}-23$ \\
\hline & & $16 q 24.2$ & 87225139 & rs4843227 & LOC101928708 & intergenic & 22723 & $1.16 \mathrm{E}-13$ \\
\hline & & 19p13.2 & 13109763 & rs68175985 & NFIX & intronic & 21777 & 3.27E-11 \\
\hline & & $5 q 15$ & 92866553 & rs62369942 & NR2F1-AS1 & ncRNA_intronic & 21664 & $4.32 \mathrm{E}-10$ \\
\hline & \multirow{3}{*}{ inferior parietal } & $20 q 13.2$ & 52448936 & rs6097618 & SUMO1P1 & intergenic & 22701 & $2.09 \mathrm{E}-17$ \\
\hline & & $12 q 14.3$ & 65797096 & rs2336713 & MSRB3 & intronic & 22701 & $2.47 \mathrm{E}-13$ \\
\hline & & $3 q 13.11$ & 104724634 & rs971551 & ALCAM & intergenic & 22701 & $2.34 \mathrm{E}-10$ \\
\hline & \multirow{3}{*}{ supramarginal } & $15 q 14$ & 39632013 & rs71471500 & THBS1 & intergenic & 22645 & $9.71 \mathrm{E}-28$ \\
\hline & & $14 q 23.1$ & 59627631 & rs2164950 & $D A A M 1$ & intergenic & 22645 & $3.59 \mathrm{E}-20$ \\
\hline & & $3 q 24$ & 147106319 & rs2279829 & ZIC4 & UTR3 & 22645 & $5.36 \mathrm{E}-18$ \\
\hline & \multirow{4}{*}{ postcentral } & $15 q 14$ & 39633904 & rs2033939 & THBS1 & intergenic & 22662 & $4.34 \mathrm{E}-133$ \\
\hline & & $3 q 24$ & 147106319 & rs2279829 & ZIC4 & UTR3 & 22662 & $2.54 \mathrm{E}-17$ \\
\hline & & $9 q 21.13$ & 76144318 & rs67286026 & ANXA1 & intergenic & 22662 & $5.03 \mathrm{E}-11$ \\
\hline & & $2 q 36.3$ & 226563259 & rs16866701 & NYAP2 & intergenic & 22545 & 5.69E-11 \\
\hline & \multirow{4}{*}{ precuneus } & $14 q 23.1$ & 59628609 & rs74826997 & $D A A M 1$ & intergenic & 22803 & $4.85 \mathrm{E}-20$ \\
\hline & & $3 q 28$ & 190663557 & rs35055419 & OSTN & intergenic & 22428 & $2.02 \mathrm{E}-10$ \\
\hline & & $2 \mathrm{p} 22.2$ & 37818236 & rs2215605 & CDC42EP3 & intergenic & 22803 & $3.43 \mathrm{E}-10$ \\
\hline & & $3 q 13.11$ & 104713881 & rs12495603 & ALCAM & intergenic & 22803 & $9.71 \mathrm{E}-10$ \\
\hline \multirow{10}{*}{ occipital } & lateral occipital & $14 q 23.1$ & 59627631 & rs2164950 & $D A A M 1$ & intergenic & 22799 & $6.89 \mathrm{E}-16$ \\
\hline & \multirow{2}{*}{ lingual } & $14 q 23.1$ & 59625997 & rs73313052 & $D A A M 1$ & intergenic & 22805 & $1.06 \mathrm{E}-20$ \\
\hline & & $6 q 22.32$ & 127089401 & rs2223739 & RSPO3 & intergenic & 22805 & $1.75 \mathrm{E}-10$ \\
\hline & \multirow{3}{*}{ cuneus } & $14 q 23.1$ & 59625997 & rs73313052 & $D A A M 1$ & intergenic & 22799 & $4.59 E-43$ \\
\hline & & 11p15.3 & 12072213 & rs11022131 & $D K K 3$ & intergenic & 22799 & $5.96 \mathrm{E}-12$ \\
\hline & & $13 q 31.1$ & 80192236 & rs9545156 & LINC01068 & intergenic & 22799 & $4.09 \mathrm{E}-10$ \\
\hline & \multirow{4}{*}{ pericalcarine } & $14 q 23.1$ & 59628679 & rs76341705 & $D A A M 1$ & intergenic & 22824 & $1.39 E-29$ \\
\hline & & $13 q 31.1$ & 80191873 & rs9545155 & LINC01068 & intergenic & 22824 & $2.25 \mathrm{E}-13$ \\
\hline & & $11 p 14.1$ & 30876113 & rs273594 & $D C D C 5$ & intergenic & 22824 & $3.51 \mathrm{E}-13$ \\
\hline & & 1p13.2 & 113208039 & rs12046466 & CAPZA1 & intronic & 22824 & $2.36 \mathrm{E}-12$ \\
\hline
\end{tabular}


bioRxiv preprint first posted online Sep. 9, 2018; doi: http://dx.doi.org/10.1101/409649. The copyright holder for this preprint (which was not peer-reviewed) is the author/funder, who has granted bioRxiv a license to display the preprint in perpetuity.

\begin{tabular}{|c|c|c|c|c|c|c|c|}
\hline & isp3zâde av & ilablestoder a & 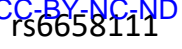 & q=oxternation & isentergenic & 22824 & $3.85 \mathrm{E}-11$ \\
\hline & $11 q 22.3$ & 104012656 & rs1681464 & PDGFD & intronic & 22824 & $7.51 \mathrm{E}-11$ \\
\hline & $6 q 22.32$ & 127096181 & rs9401907 & RSPO3 & intergenic & 22824 & $2.11 \mathrm{E}-10$ \\
\hline & $7 p 21.1$ & 18904400 & rs12700001 & HDAC9 & intronic & 22824 & $2.12 \mathrm{E}-10$ \\
\hline & $5 q 12.1$ & 60315823 & rs10939879 & NDUFAF2 & intronic & 22824 & $2.92 \mathrm{E}-10$ \\
\hline caudal anterior cingulate & $5 q 14.3$ & 82852578 & rs309588 & VCAN & intronic & 22748 & $2.60 \mathrm{E}-10$ \\
\hline insula & $11 q 23.1$ & 110949402 & rs321403 & C11orf53 & intergenic & 22543 & $9.58 \mathrm{E}-12$ \\
\hline IIIsuld & $8 q 24.12$ & 120596023 & rs10283100 & ENPP2 & exonic & 21481 & 8.29E-11 \\
\hline
\end{tabular}

$\mathrm{N}$ : number of individuals in meta-analysis; pDiscovery: p-value of discovery GWAS meta-analysis in

CHARGE; banksts: banks of the superior temporal sulcus. 
bioRxiv preprint first posted online Sep. 9, 2018; doi: http://dx.doi.org/10.1101/409649. The copyright holder for this preprint (which was not peer-reviewed) is the author/funder, who has granted bioRxiv a license to display the preprint in perpetuity.

It is made available under a CC-BY-NC-ND 4.0 International license.
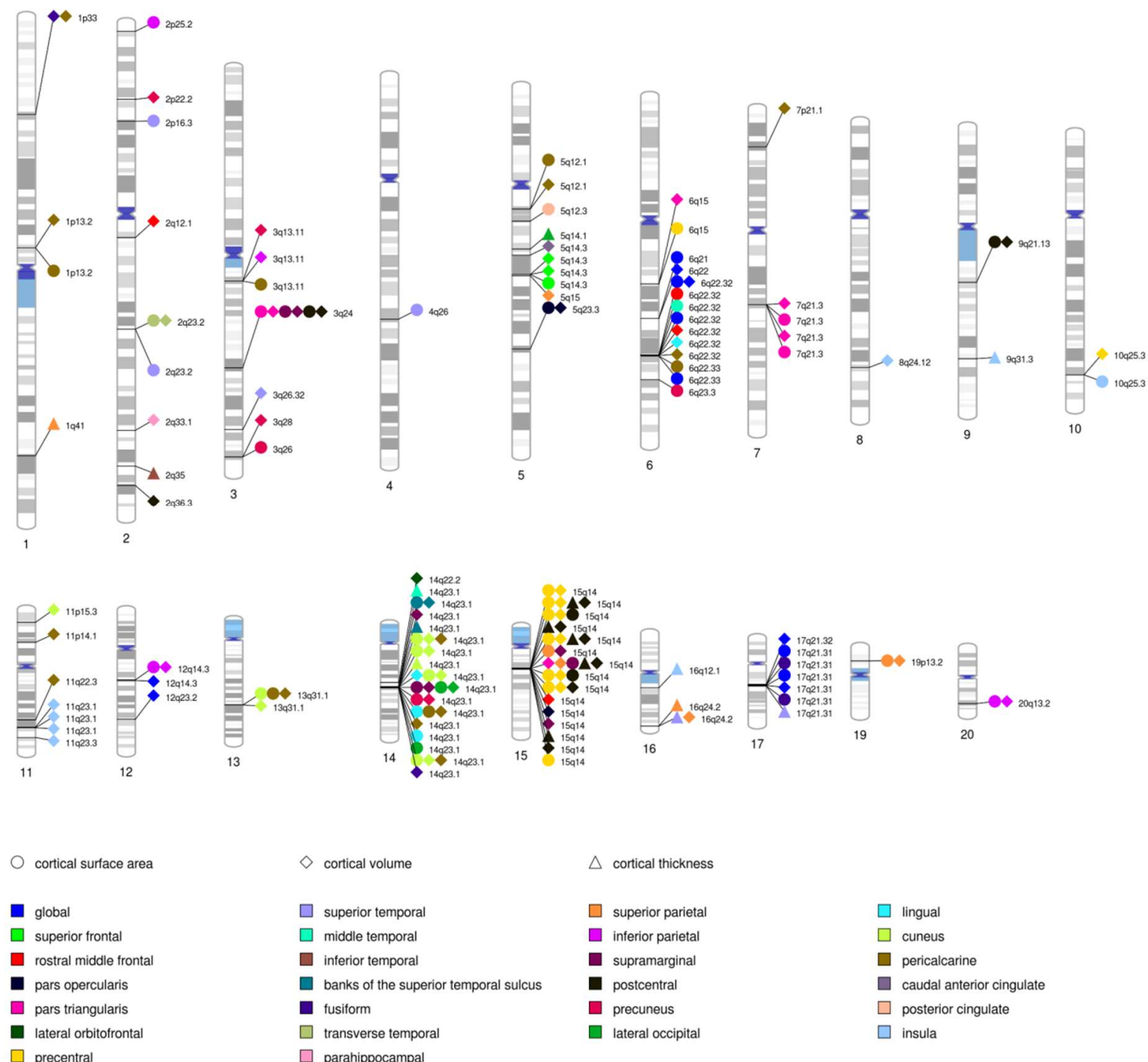

$\diamond$ cortical volume
$\square$ superior temporal
$\square$ middle temporal
$\square$ inferior temporal
$\square$ banks of the superior temporal sulcus
$\square$ fusiform
$\square$ transverse temporal
$\square$ parahippocampal

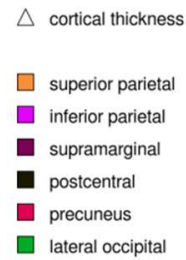

$\square$ lingual

$\square$ cuneus

$\square$ pericalcarine

$\square$ caudal anterior cingulate

$\square$ posterior cingulate

$\square$ insula

Figure 1. Chromosomal ideogram annotated with genome-wide significant associations

$\left(\mathrm{p}_{\text {Discovery }}<1.09 \times 10^{-9}\right)$ and corresponding genomic loci. 
bioRxiv preprint first posted online Sep. 9, 2018; doi: http://dx.doi.org/10.1101/409649. The copyright holder for this preprint (which was not peer-reviewed) is the author/funder, who has granted bioRxiv a license to display the preprint in perpetuity.

\section{It is made available under a CC-BY-NC-ND 4.0 International license.}
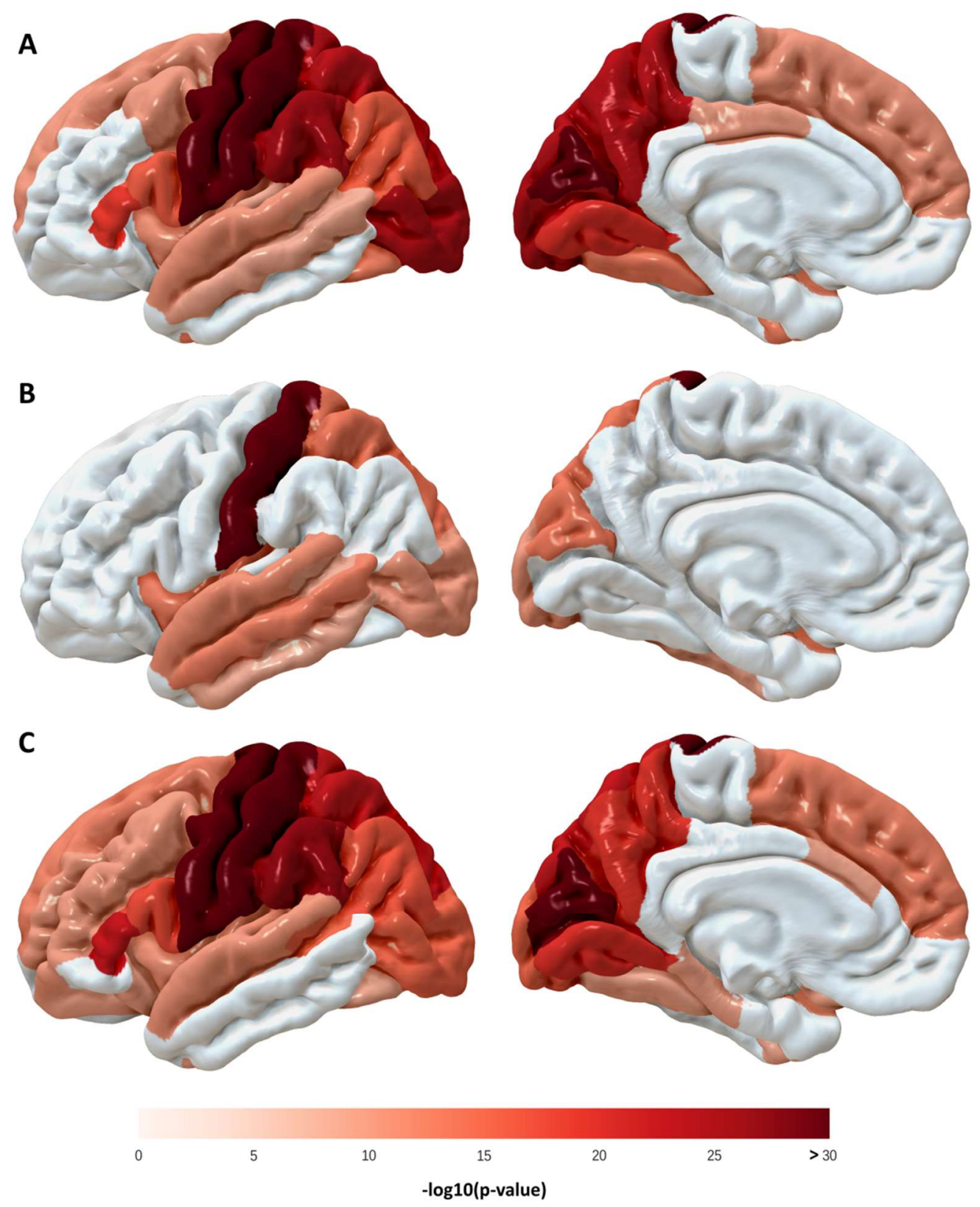

Figure 2. Lowest p-value of cortical surface area (A), thickness (B) and (C) volume of each cortical region. 
bioRxiv preprint first posted online Sep. 9, 2018; doi: http://dx.doi.org/10.1101/409649. The copyright holder for this preprint (which was not peer-reviewed) is the author/funder, who has granted bioRxiv a license to display the preprint in perpetuity. It is made available under a CC-BY-NC-ND 4.0 International license.
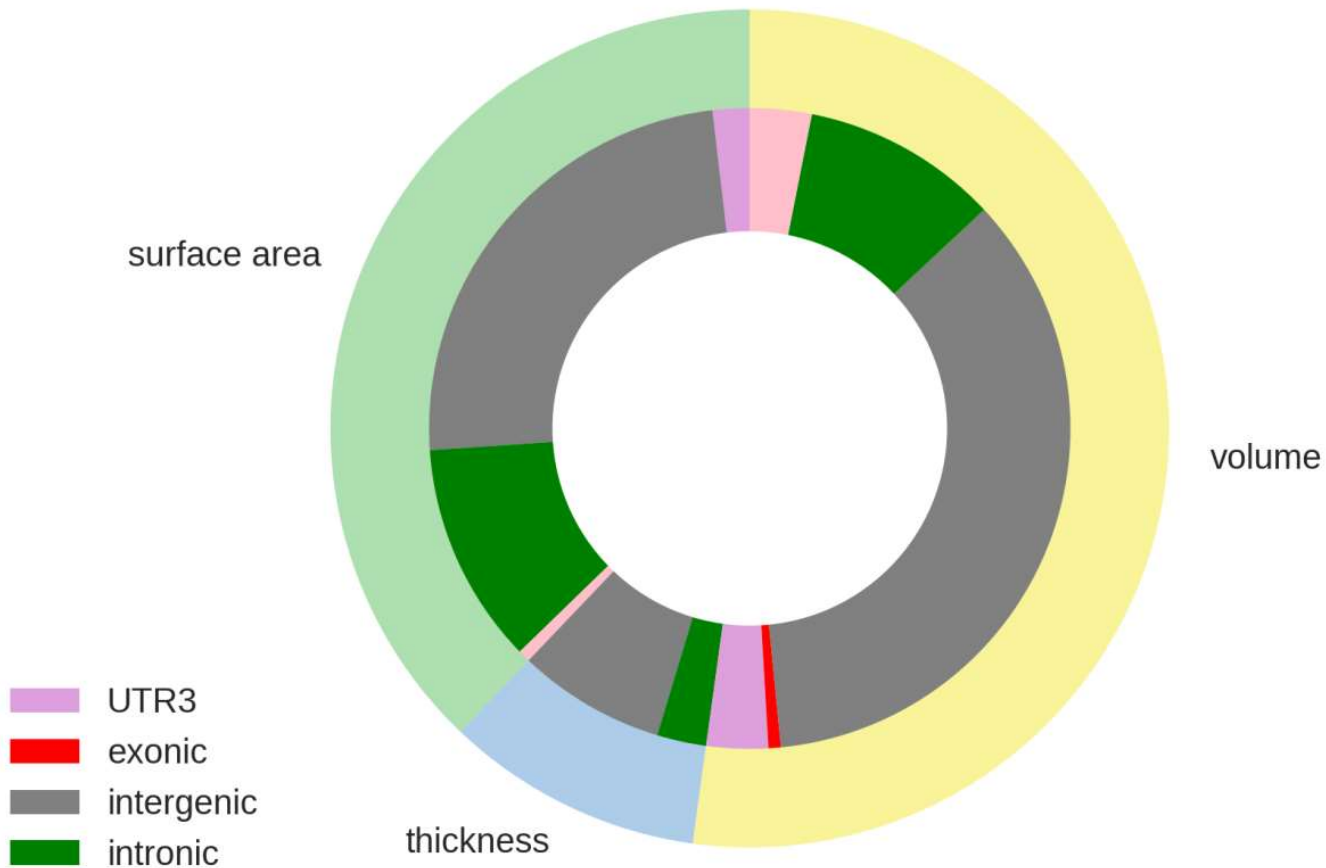

ncRNA intronic

Figure 3. Proportion of functional annotation categories for global and regional cortical thickness, surface area and volume assigned by ANNOVAR. 
bioRxiv preprint first posted online Sep. 9, 2018; doi: http://dx.doi.org/10.1101/409649. The copyright holder for this preprint (which was not peer-reviewed) is the author/funder, who has granted bioRxiv a license to display the preprint in perpetuity.

It is made available under a CC-BY-NC-ND 4.0 International license.
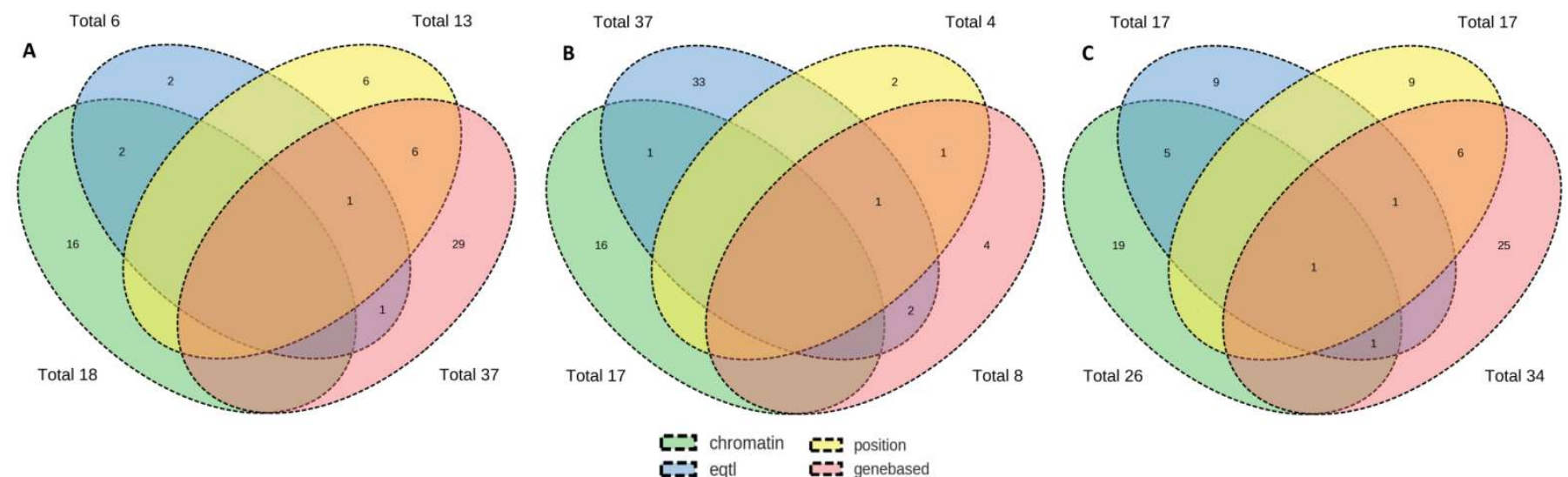

Figure 4. Number of overlapping genes between FUMA eQTL mapping, FUMA chromatin interaction mapping, ANNOVAR chromosome positional mapping and MAGMA gene based analysis for all cortical regions combined for cortical surface area (A), thickness (B) and volume (C). 